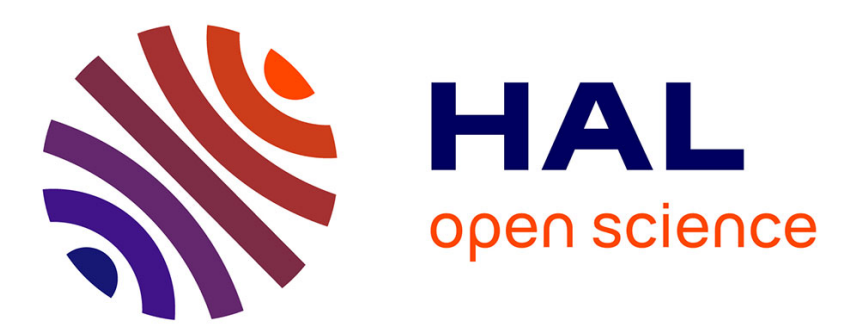

\title{
Tracing of $\mathrm{Cl}$ input into the sub-arc mantle through the combined analysis of $\mathrm{B}, \mathrm{O}$ and $\mathrm{Cl}$ isotopes in melt inclusions
}

Anne-Sophie Bouvier, Mélina Manzini, Estelle F. Rose-Koga, Alexander R.L. Nichols, Lukas Baumgartner

\section{To cite this version:}

Anne-Sophie Bouvier, Mélina Manzini, Estelle F. Rose-Koga, Alexander R.L. Nichols, Lukas Baumgartner. Tracing of $\mathrm{Cl}$ input into the sub-arc mantle through the combined analysis of $\mathrm{B}, \mathrm{O}$ and $\mathrm{Cl}$ isotopes in melt inclusions. Earth and Planetary Science Letters, 2019, 507, pp.30-39. 10.1016/j.epsl.2018.11.036 . hal-02014541

\author{
HAL Id: hal-02014541 \\ https://hal.uca.fr/hal-02014541
}

Submitted on 17 Nov 2020

HAL is a multi-disciplinary open access archive for the deposit and dissemination of scientific research documents, whether they are published or not. The documents may come from teaching and research institutions in France or abroad, or from public or private research centers.
L'archive ouverte pluridisciplinaire HAL, est destinée au dépôt et à la diffusion de documents scientifiques de niveau recherche, publiés ou non, émanant des établissements d'enseignement et de recherche français ou étrangers, des laboratoires publics ou privés. 
4 Anne-Sophie Bouvier ${ }^{1 *}$, Mélina Manzini ${ }^{1}$, Estelle F. Rose-Koga ${ }^{2}$, Alexander R.L. Nichols ${ }^{3}$, $5 \quad$ Lukas P. Baumgartner ${ }^{1}$

${ }^{1}$ Institut des Sciences de la Terre, Université de Lausanne, Switzerland

${ }^{2}$ Laboratoire Magmas et Volcans, Université Clermont Auvergne, France

${ }^{3}$ Department of Geological Sciences, University of Canterbury, New Zealand

\section{Abstract}

The effect that recycling crust and sediments have on the composition of the mantle wedge, in particular in terms of volatiles, is still debated. Chlorine, an important fluid mobile element that has stable isotopes with different concentrations in the terrestrial reservoirs, has the potential to be used to trace slab-derived fluids.

Olivine-hosted melt inclusions (OHMIs) provide a first order constraint on the $\delta^{37} \mathrm{Cl}$ of 17 primary magmas, since they are unaffected by near surface processes. In this study, $\delta^{37} \mathrm{Cl}$ were coupled with $\delta^{11} \mathrm{~B}$ and $\delta^{18} \mathrm{O}$ analyses in samples from the Lesser Antilles, Vanuatu, Aeolian, NE Japan and Izu-Bonin arcs. This unique dataset is used to better understand the large $\delta^{37} \mathrm{Cl}$ variation in melt inclusions from a single sample. OHMIs from the Vulcano 21 (Aeolian arc) and Sukumoyama (Izu-Bonin arc) samples have similar $\delta^{37} \mathrm{Cl}(-2.5 \pm 0.5 \%$ and 2.6 $\pm 0.8 \%$, respectively). These are different from $\delta^{37} \mathrm{Cl}$ in OHMIs from the other three localities $\left(\delta^{37} \mathrm{Cl}\right.$ of $-0.7 \pm 0.6 \%$ for Aoba (Vanuatu arc) and St. Vincent (Lesser Antilles arc), - 
$1 \pm 0.9 \%$ for Iwate (NE Japan)). Vulcano OHMIs also have statistically different B and O isotope compositions compared to those from the other locations: average $\delta^{11} \mathrm{~B}$ of $-5.1 \pm 2.9 \%$ o for Vulcano OHMIs, compared to $2.5 \pm 3.7 \%$, $5.2 \pm 1.4 \%$ o, $7.0 \pm 2.2 \%$, $3.8 \pm 7.5 \%$ for Sukumoyama, Iwate, Aoba and St. Vincent OHMIs, respectively. All OHMIs have $\delta^{18} \mathrm{O}$ between 4.0 and 7.4\%, except for those from Vulcano, which are significantly different, with $\delta^{18} \mathrm{O}$ from 7.2 to $9.1 \%$. Combining these three stable isotope systems suggests that the large variation $\left(>2 \%\right.$ ) of $\delta^{37} \mathrm{Cl}$ in $\mathrm{OHMIs}$ from a sample reflects inputs from different sources of $\mathrm{Cl}$ rather than heterogeneities in a single main source. Variability between arcs might reflect different major sources of $\mathrm{Cl}$.

Comparing OHMIs $\mathrm{Cl}$ isotope data from the Aeolian and Izu-Bonin arcs with existing bulk rock $\mathrm{Cl}$ isotope data suggest that OHMIs preserve the source signature of $\mathrm{Cl}$ input whereas this signal can be lost in whole rocks as a result of $\mathrm{Cl}$ isotope diffusive fractionation during $\mathrm{Cl}$ degassing. SIMS measurements of $\mathrm{Cl}$ isotopes in OHMIs could thus help refine models of $\mathrm{Cl}$ cycles in the mantle.

Keywords: melt inclusions; chlorine isotopes; oxygen isotopes; boron isotopes; subduction zones; SIMS

\section{Introduction}

Chlorine has been widely studied as an element in volcanic systems (e.g., Aiuppa et al., 2009; Mather et al., 2012), but to date only a few studies have reported $\mathrm{Cl}$ isotopes (noted $\left.\delta^{37} \mathrm{Cl}\right)$ in rocks and minerals and used them to make petrogenetic interpretations ( $\sim 35$ papers since 1995 and a few pioneering works prior to that). After some debate about the $\mathrm{Cl}$ isotope values of the terrestrial reservoirs, refinement of bulk rock analytical techniques has brought 
scientists to a consensus on the relatively narrow range of $\delta^{37} \mathrm{Cl}$ found in terrestrial rocks (Figure 1 and Supplementary material 1). In subduction zones, $\mathrm{Cl}$, a soluble element, could serve as a tracer of different $\mathrm{Cl}$ sources that contaminate the mantle wedge. Based on theoretical calculations (Schauble et al., 2003) and experimental work (Liebscher et al., 2006), fractionation of $\mathrm{Cl}$ isotopes between silicates and $\mathrm{NaCl}$ at $\mathrm{T}>300^{\circ} \mathrm{C}$ should be limited. This implies that $\delta^{37} \mathrm{Cl}$ should not be (or only slightly) fractionated during slab dehydration (Barnes et al., 2006; Bonifacie et al., 2008; John et al., 2011). The isotopic composition of a metasomatized mantle should thus reflect simple binary mixing between the host rock and the metasomatizing agent. The $\delta^{37} \mathrm{Cl}$ of arcs lavas vary from -2.6 to $+3.0 \%$ o (e.g., Barnes et al., 2009; Barnes and Straub, 2010). These studies have been used to estimate the $\mathrm{Cl}$ reservoirs and suggested that $\mathrm{Cl}$ could be derived from altered oceanic crust (AOC), serpentinites or sediments, depending on the depth of fluid extraction, which leads to a change in $\delta^{37} \mathrm{Cl}$ across an arc (Barnes et al., 2008). Variation along the Central America volcanic arc has also been observed and has been used to suggest different sources of $\mathrm{Cl}$ along the arc (Barnes et al., 2009).

Recently, Manzini et al. (2017) reported $\delta^{37} \mathrm{Cl}$ in olivine-hosted melt inclusions (OHMIs) from three different arc settings (the Lesser Antilles, Aeolian and Vanuatu arcs). Their study reported large intra-sample $\delta^{37} \mathrm{Cl}$ variations (up to $2.5 \%$, Figure 1) that are half of the variation exhibited by all the bulk rocks from arc settings measured to date. Two arcs display similar $\delta^{37} \mathrm{Cl}\left(-1.9\right.$ to $+0.6 \%$ ), whereas the third one has significantly different $\delta^{37} \mathrm{Cl}$ compositions (-3.4 to $-2.0 \%$ ). These authors suggested that for the Lesser Antilles and Vanuatu arcs, $\delta^{37} \mathrm{Cl}$ in the OHMIs reflect the imprint of serpentinite (and/or AOC) whereas for the Aeolian arc, $\delta^{37} \mathrm{Cl}$ is influenced by sediments. The difference between the two different sets of compositions might reflect the different slab geometries that the arcs have. 
As pointed out by Manzini et al. (2017), further work was required to better understand the different $\delta^{37} \mathrm{Cl}$ compositions between the three different arcs, as well as the relatively large variation observed within a sample. Also, new data published for bulk rocks in the Aeolian arc show large $\delta^{37} \mathrm{Cl}$ difference between Stromboli lavas (-0.96 to $+0.69 \%$; Liotta et al., 2017) and Stromboli OHMIs (-3.2 to $-1.75 \%$; Manzini et al., 2017). In order to understand the large variations and assess how representative the $\delta^{37} \mathrm{Cl}$ values recorded in OHMIs are, this study couples $\delta^{37} \mathrm{Cl}$ data obtained by Manzini et al. (2017) with $\delta^{11} \mathrm{~B}$ and $\delta^{18} \mathrm{O}$ obtained in the same OHMIs. In addition, new $\mathrm{Cl}, \mathrm{B}$ and $\mathrm{O}$ data from two additional arcs (Izu-Bonin and NE Japan) have been acquired. Oxygen isotopes do not largely fractionate during dehydration at high temperature (e.g., Liebscher et al., 2006; Schauble et al., 2003; Zheng, 1993). Comparison of these two isotopic systems allows sediment vs. AOC/serpentinite influences to be identified. In contrast to $\mathrm{O}$ and $\mathrm{Cl}$ isotopes, $\mathrm{B}$ isotopes largely fractionate during dehydration (e.g., Ishikawa \& Nakamura, 1994; Peacok \& Hervig, 1999), complicating the data interpretation due to the lack of B isotope partitioning data in the different phases involved. However, B isotopes have the potential to distinguish between AOC and serpentinites end-members as their respective bulk rocks are different (Boschi et al., 2013; Chaussidon \& Jambon, 1994; Smith et al., 1995; Vils et al., 2009). This unique dataset combining $\mathrm{Cl}$ isotopes with two other stable isotope systems in melt inclusions is used to assess if variations of $\delta^{37} \mathrm{Cl}$ in melt inclusions within a sample represent heterogeneities in a single, major, $\mathrm{Cl}$ reservoir, or alternatively reflect that $\mathrm{Cl}$ is added to the mantle wedge from different sources. Disparities between the whole rocks and OHMIs are also discussed in terms of analytical artefacts and/or fractionation due to diffusion.

\section{Geological context and sample descriptions}


All samples were previously studied and their geological settings are well-known. They were chosen as they contain glassy OHMIs with basaltic compositions, potentially providing access to Cl-undegassed melts. The different arcs have been chosen to represent various amounts of fluids involved in their magma genesis (see section 2.1). They are thus suitable samples to test whether $\delta^{37} \mathrm{Cl}$, coupled with other isotopic systems, could be a useful tracer of $\mathrm{Cl}$ sources and the fate of $\mathrm{Cl}$ in subduction zones.

\subsection{Melt inclusions from previous studies}

OHMIs from St. Vincent (Lesser Antilles arc), Vulcano (Aeolian arc) and Aoba (Vanuatu arc) are the same as those reported by Manzini et al. (2017). OHMIs from Iwate Volcano (NE Japan arc) were analyzed for volatiles by Rose-Koga et al. (2014). Nomenclature of each OHMI is identical to their original papers.

The intra-oceanic volcanic arc of the Lesser Antilles arc is generated by the subduction of the Atlantic Plate beneath the Caribbean Plate (see Macdonald et al., 2000 for a review). Analyzed OHMIs were separated from a lapilli deposit collected near Troumaka Bay, in St. Vincent, where high-MgO basalts occur. Based on B isotopes, Bouvier et al. (2008) suggested that fluids involved in the magma genesis are derived from serpentinites, sediments and AOC. The Aeolian arc is related to the subduction of the Ionian-Adriatic lithosphere underneath the Calabrian arc. Mantle beneath the Aeolian arc volcanoes has been metasomatised by fluids from the Ionian oceanic crust and the sediments from the Ionian basin in the eastern part of the arc (Peccerillo et al., 2013). The selected OHMIs come from La Sommata scoria cone on Vulcano Island. OHMIs from Stromboli, analyzed for $\delta^{37} \mathrm{Cl}$ by Manzini et al. (2017), were not included in this study as they were too small to undergo further analysis.

The Vanuatu arc is generated by the northeastward subduction of the Australian Plate beneath the Pacific Plate. The selected olivine crystals come from three different lapilli layers 
of Aoba Island (Ao3 from an eruptive fissure on the volcano north flank; Ao15 from Torgil tuff ring; and Ao17 from Red Cliff pyroclastic sequence; Sorbadere et al., 2011). Slab fluids beneath Aoba involved fluids derived from serpentinites (Métrich and Deloule, 2014).

NE Japan arc is generated by the subduction of the Pacific Plate beneath the Okhotsk Plate. The sample, coming from arc front Iwate Volcano, was studied by Rose-Koga et al. (2014). These authors showed that fluids from the slab beneath Iwate Volcano are derived from AOC and sediments. The selected OHMIs have already been analyzed for major and volatiles elements, and $\mathrm{Pb}$ isotopes, and have been chosen based on their size - they have to be large enough to place a $\delta^{37} \mathrm{Cl}$ SIMS spots in between previous SIMS spots.

\subsection{New melt inclusions from Izu-Bonin arc}

New data for OHMIs from a sample collected from the Sukumoyama scoria cone in the Higashi-Izu Monogenetic Volcano Field (HIMVF), on the northeastern Izu Peninsula, were used in this study. The Izu-Bonin arc is an intraoceanic arc generated by the subduction of the Pacific Plate beneath the Philippine Sea Plate. Since 15 Ma, the Izu-Bonin arc has been colliding with the Honshu Arc in central Japan to form the Izu collision zone. OHMIs from sample IZ27-15 on Sukumoyama were analyzed previously for major, volatile and trace elements (Nichols et al., 2012). Compositional variations were suggested to reflect interstitial melts within the crystal mush of the magma chamber experiencing distinct crystallization histories and variability between contributions from fluid and sediment melt components in the source. For this study, new OHMIs were polished and analyzed from the same sample used by Nichols et al. (2012).

\section{Methods}


Olivine crystals from the $0.5-1 \mathrm{~mm}$ grain size fraction of crushed scoria were hand-picked under a binocular microscope and embedded in epoxy. Olivine crystals containing naturally glassy OHMIs were polished individually in order to expose the OHMI on the surface. Most OHMIs contain a shrinkage bubble, but none contain daughter minerals. Each polished

olivine was removed from epoxy and pressed into indium, along with various reference materials for secondary ion mass spectrometry (see below). Each analytical method applies for all OHMIs.

\subsection{Electron microprobe (EMPA)}

Major element compositions of the MIs and their host olivine were acquired by electron microprobe (EMPA) using a JEOL 8200 Superprobe. For the MIs, analytical conditions were $15 \mathrm{kV}, 10 \mathrm{nA}$ current and a $5 \mu \mathrm{m}$ beam while conditions were $15 \mathrm{kV}, 15 \mathrm{nA}, 1 \mu \mathrm{m}$, for the olivine host. Peak counting times were $30 \mathrm{~s}$ on all elements, except for K, Na and $\mathrm{Ca}(20 \mathrm{~s})$. Backgrounds were counted for 15 or $10 \mathrm{~s}(\mathrm{Si}, \mathrm{Fe}, \mathrm{Na}, \mathrm{Ca}, \mathrm{K}) . \mathrm{Cl}$ was determined by EMPA only in OHMIs analyzed by Manzini et al. (2017); for other OHMIs, Cl content was measured using SIMS. For the MIs, the KL2-G glass standard (Jochum et al., 2006) was used to calibrate $\mathrm{SiO}_{2}$ and $\mathrm{Al}_{2} \mathrm{O}_{3}$. Other elements were calibrated on different minerals. ML3B-G (Jochum et al., 2006) and San Carlos olivine were used as internal standards to check the calibration.

\subsection{Secondary Ion Mass Spectrometry (SIMS)}

Boron, $\mathrm{Cl}$ and $\mathrm{O}$ isotope ratios were measured by secondary ion mass spectrometry (SIMS) using the CAMECA IMS 1280-HR at the SwissSIMS laboratory (University of Lausanne, Switzerland). A $1.5-2 \mathrm{nA}, 10 \mathrm{kV} \mathrm{Cs}^{+}$primary beam was used to analyze $\mathrm{Cl}$ and $\mathrm{O}$ isotope ratios, over two different sessions. The electron flood gun, with normal incidence, was used to compensate charges. For $\delta^{37} \mathrm{Cl}$, the analytical method was the same as described in 
Manzini et al. (2017). To summarize, a pre-sputtering of $240 \mathrm{~s}$ with a $25 \mu \mathrm{m}$ raster size was used in order to remove all the possible $\mathrm{Cl}$ contamination. Analysis time was $240 \mathrm{~s}$ with a 10 $\mu \mathrm{m}$ raster. ${ }^{35} \mathrm{Cl}^{-}$and ${ }^{37} \mathrm{Cl}^{-}$were measured simultaneously on two Faraday cups (FCs), using $10^{11} \Omega$ resistors, with a mass resolving power (MRP) set to $\sim 3000$. The internal uncertainty (single measurement) for the samples was $0.15-0.5 \%$ (two standard errors, 2 s.e.), depending on the $\mathrm{Cl}$ content. Reproducibility (point to point) was checked using an in-house $\mathrm{Cl}$-enriched standard UNIL_Gl-B7. Reproducibility of UNIL_Gl-B7 over eight points at the beginning of each session was $<0.2 \%$ (two standard deviations, noted 2 SD hereafter), but up to $0.35 \%$ o 2SD over a session (24-36h; two measurements of UNIL_Gl-B7 every six unknowns). Instrumental mass fractionation (IMF), depending on $\mathrm{Si}, \mathrm{K}$, and $\mathrm{Al}$ mole content of the glasses was calibrated using six glass standards (Manzini et al., 2017), including UNIL-Gl-B7 at the beginning of each session (SM 2A). To that purpose, UNIL_Gl-B4, UNIL_Gl-B6, RMR, PR2 and IB94 were measured four times at the beginning of each session, with two measurements of UNIL_Gl-B7 in between each different glasses. To ensure the validity of the calibration over the session and determine the uncertainty of the calibration, UNIL_Gl-B6 and UNIL_Gl-B4 were measured repeatedly over the session. A reproducibility of $0.3 \%$ and a maximum uncertainty of $0.4 \%$ were calculated. The IMF applied to each OHMIs was calculated based on their major element composition, measured by EMPA before the SIMS sessions. $\delta^{37} \mathrm{Cl}$ is referenced to the standard mean ocean chloride (SMOC) ${ }^{37} \mathrm{Cl} /{ }^{35} \mathrm{Cl}$ ratio of 0.319592 .

The $\mathrm{Cl}$ content of each OHMI could be estimated based on the ${ }^{35} \mathrm{Cl}$ count per second normalized to the primary beam intensity and compared to the standards. As the estimation by SIMS gives satisfactory results for $\mathrm{Cl}$ content $<3000 \mathrm{ppm}$ (SM 2B), SIMS was used to estimate the $\mathrm{Cl}$ contents of the new Sukumoyama OHMIs, which should have relatively low $\mathrm{Cl}$ contents based on those previously analyzed (Nichols et al., 2012). 
${ }^{16} \mathrm{O}$ and ${ }^{18} \mathrm{O}$ secondary ions were analyzed at $2400 \mathrm{MRP}$ and collected on two FCs in multi-collection mode using $10^{10}$ and $10^{11} \Omega$ resistors, respectively. The FCs were calibrated at the beginning of the session, using the calibration routine. Mass calibration was performed at the beginning of each session $(<12 \mathrm{~h})$. Each analysis takes $\sim 4$ minutes, including presputtering (30 s) and automated centering of secondary electrons. Ion mass fractionation was calibrated using several standards with different major element compositions (SM 2C). Reproducibility of the standards is better than $0.3 \%$. $\delta^{18} \mathrm{O}$ is referenced to the standard mean ocean water $(\mathrm{SMOW}){ }^{18} \mathrm{O} /{ }^{16} \mathrm{O}$ ratio of $2005.2 \times 10^{-6}$.

To determine $\delta^{11} \mathrm{~B},{ }^{10} \mathrm{~B}$ and ${ }^{11} \mathrm{~B}$ were measured in multicollection mode, using two electron multipliers. The $\mathrm{O}^{-}$primary beam intensity was $8 \mathrm{nA}$ and mass resolution was set at 2400 . A single analysis (60 cycles) took 16 minutes. The instrumental isotopic fractionation was determined by analyzing five standards with different major element compositions (SM 2D). As already reported in the literature, instrumental isotopic fractionation was observed to be independent of major element composition (Rosner et al., 2008). Reproducibility on the standards varies from 2 to $4 \%$ (2SD), depending on the B content of individual melt inclusions. $\delta^{11} \mathrm{~B}$ is referenced to the NBS $951{ }^{11} \mathrm{~B} /{ }^{10} \mathrm{~B}$ ratio of 4.044 .

Amongst the standards used for $\delta^{11} \mathrm{~B}$ and $\delta^{18} \mathrm{O}$ calibrations, BHVO-2G and BCR-2G, with compositions encompassing those of our OHMIs, were also included in the sample mounts, as well as in the standard mount. During the session measuring $\delta^{18} \mathrm{O}$ and $\delta^{11} \mathrm{~B}$, several analyses of BHVO-2G and BCR-2G were undertaken before and after a maximum of 18 unknowns to monitor instrument stability (i.e., magnetic field stability). These standards were also treated as unknowns to check the accuracy of the calibration. Accuracies were similar to reproducibility: $0.3 \%$ for $\delta^{18} \mathrm{O}$ and $3 \%$ for $\delta^{11} \mathrm{~B}$. 
All major elements, as well as details of the post-entrapment crystallization (PEC) corrections are reported in SMs 3-4. Compared to whole rocks from each locality, OHMIs plot at the primitive end of the differentiation trends (SM 5), and have basanite to basaltic compositions (Figure 2). The OHMIs from the different settings define distinct trends that show variable alkali enrichment, with some of St. Vincent OHMIs being the most alkali-rich, and those from Iwate Volcano, NE Japan arc, the most alkali-poor.

Manzini et al. (2017) showed that the highest and most variable $\mathrm{Cl}$ contents are in OHMIs from Aoba (0.06 to $0.39 \mathrm{wt} \%)$ and Vulcano (0.14 to $0.44 \mathrm{wt} \%)$ islands, whereas in St. Vincent samples the range is more restricted (0.08 to $0.15 \mathrm{wt} \%)$. Rose-Koga et al. (2014) reported 0.03 to $0.05 \mathrm{wt} \%$ for Iwate OHMIs. The new data for OHMIs from Sukumoyama provide $\mathrm{Cl}$ contents from 0.04 to $0.09 \mathrm{wt} \%$, similar to the values published by Nichols et al. (2012).

\subsection{Stable isotope compositions}

\subsubsection{Chlorine isotopes}

All stable isotope compositions are reported in Table 1. The six new data from Iwate Volcano range from $-2.1 \pm 0.8 \%$ ( 2 s.e.) to $0.5 \pm 0.8 \%$ o ( 2 s.e.) (average of $-1 \%$ ), similar to St. Vincent and Aoba OHMIs. The nine data from Sukumoyama OHMIs show distinct values compare to Iwate Volcano OHMIs, ranging from $-4.4 \pm 0.5 \%$ o $(2$ s.e. $)$ to $-1.6 \pm 0.4 \%$ o (2 s.e.) (average of $-2.3 \%$ ), more similar to Vulcano. As for Vulcano OHMIs, Cl isotopes for Sukumoyama OHMIs can be compared to $\delta^{37} \mathrm{Cl}$ bulk rock values. Indeed, lavas from two volcanoes, Oshima and Niijima, located relatively close to Sukumoyama, at the northern end 
lavas have significantly higher $\mathrm{Cl}$ isotope compositions $(-0.28 \%$ and $-0.77 \%$, respectively) compared to Sukumoyama OHMIs.

The lowest $\delta^{37} \mathrm{Cl}$ value measured for a Sukumoyama OHMI, $-4.4 \pm 0.5 \%$ ( 2 s.e.), is the lowest measured for any OHMI to date and also lower than bulk rock values for solid geological samples (Figure 1). This value has been carefully checked to assess its validity: all SIMS analytical conditions are similar to other MIs measurements (secondary deflectors, primary intensity, topography, etc). Despite the fact that this inclusion also has the lowest $\mathrm{Cl}$ content of Sukumoyama MIs (400 ppm), analytical artefact due to low $\mathrm{Cl}$ content is discarded: internal error (counting statistic of a single measurement; $0.5 \%$, 2 s.e.) is similar to the internal error of other OHMIs from this sample. Additionally, some Iwate OHMIs have as low as, or even lower, $\mathrm{Cl}$ contents (300-400 ppm) and yet $\delta^{37} \mathrm{Cl}$ for these inclusions is in the range of published values $(-1.6$ to $+0.5 \%$ ). Hence the value is considered to be reliable.

\subsubsection{Boron isotopes}

The lowest $\delta^{11} \mathrm{~B}$ values have been measured in the St. Vincent OHMIs, with values ranging from $-18.5 \pm 1.9$ to $+11.7 \pm 1.9 \%$ o ( 2 s.e.) (average: $+3.6 \%$ ). This range, similar to the range previously reported for St. Vincent OHMIs $(-25.6$ to $+11.8 \%$, average $0.9 \%$; Bouvier et al., 2008) is by far the largest range of $\delta^{11} \mathrm{~B}$ values reported for a group of OHMIs in this study. $\delta^{11} \mathrm{~B}$ range from $-9.5 \pm 1.9$ to $-1.0 \pm 2.1 \%$ ( 2 s.e.) (average: $-5 \%$ ) for the Vulcano OHMIs. Aoba OHMIs have positive $\delta^{11} \mathrm{~B}$ values $(+3.4$ to +12.0 , average of $+7 \%$ ), higher than the values reported for MIs from two other Aoba samples $(-11.9$ to $+6.4 \%$; Métrich and Deloule, 2014). Sukumoyama OHMIs have variable $\delta^{11} \mathrm{~B}$ values, ranging from $-4.8 \pm 4 \%$ o to $+5.8 \pm 4 \%$ ( 2 s.e.) (average: $1.7 \%$ ). Iwate Volcano OHMIs have a restricted range of positive $\delta^{11} \mathrm{~B}$ values $(+4.7 \pm 1.7 \%$ o to $+8.1 \pm 2 \%$; average: $6.3 \%$ )

\subsubsection{Oxygen isotopes}


The $\delta^{18} \mathrm{O}$ varies from $4.3 \pm 0.4$ to $6.9 \pm 0.4 \%$ ( 2 s.e.), with an average of $5.8 \%$ for the St.

Vincent OHMIs, similar to the average $(6.0 \%) \delta^{18} \mathrm{O}$ reported by Bouvier et al. (2008). Aoba OHMIs have a similar range of $\delta^{18} \mathrm{O}$ composition, from $4.4 \pm 0.2$ to $7.0 \pm 0.2 \%$ ( 2 s.e. $)$ (average: $6.3 \%$ ); and Sukumoyama OHMIs also have a similar range of $\delta^{18} \mathrm{O}(4.8 \pm 0.3$ to $7.4 \pm 0.3 \%$ o, 2 s.e.), but with slightly higher average (6.6\%o). In contrast, Iwate Volcano OHMIs have slightly lower $\delta^{18} \mathrm{O}$ values of $3.9 \pm 0.3$ to $6.6 \pm 0.3 \%$ ( 2 s.e.), with an average of $5.4 \%$. Vulcano OHMIs have the highest $\delta^{18} \mathrm{O}$ measured in this study. They vary from $6.1 \pm 0.2$ to $9.1 \pm 0.2 \%$ o ( 2 s.e. $)$, with an average value of $7.9 \%$.

\section{Discussion}

\subsection{Significance of $\delta^{37} \mathrm{Cl}$ variation in OHMIs within a sample}

Manzini et al. (2017) reported the first data of $\delta^{37} \mathrm{Cl}$ in OHMIs from arc settings and showed that $\mathrm{Cl}$ isotopes can vary by up to $2.5 \%$ within a single sample (St. Vincent). Here, the OHMIs from two new samples from Iwate Volcano and Sukumoyama have variations in $\delta^{37} \mathrm{Cl}$ of 2.6 and $2.8 \%$, respectively, further confirming that relatively large variations $(>2 \%$ o $)$ in $\mathrm{Cl}$ isotopes within $\mathrm{OHMIs}$ from a single sample might be common. Given the large range of $\delta^{37} \mathrm{Cl}$ in terrestrial $\mathrm{Cl}$ reservoirs (Figure 1), the measured variation in OHMIs within a sample could reflect either heterogeneity of a single $\mathrm{Cl}$ reservoir, or contributions from different $\mathrm{Cl}$ reservoirs. To better understand the variability of $\delta^{37} \mathrm{Cl}$ within a sample, $\mathrm{O}$ and $\mathrm{B}$ isotopes were measured in the same OHMIs. As mentioned in the introduction, comparison with $\mathrm{O}$ isotopes could help to distinguish between the influence of fluids from sediments and the influence of fluids from AOC/serpentinites, whereas B isotopes may differentiate between fluids from AOC and serpentinites.

\subsubsection{Are the measured $\delta^{37} \mathrm{Cl}$ representative of the source?}


Before any interpretation of source process(es), it is important to evaluate several potential processes that can disturb the measured $\delta^{37} \mathrm{Cl}$. First, we ensured that the selected OHMIs have not degassed $\mathrm{Cl}$. In a plot of $\mathrm{SiO}_{2}$ vs. $\mathrm{Cl}$ content of the OHMIs (Figure 3), within each sample $\mathrm{Cl}$ remains constant over the $\mathrm{SiO}_{2}$ variation. This suggests that $\mathrm{Cl}$ is not degassing from the melts as they were trapped.

Analytical artefacts were also investigated. Uncertainty in the calibration for $\mathrm{Cl}$ isotopes is $0.4 \%$ (2SD), smaller than the observed variation within a sample $(>2 \%$ ) or between samples. The absence of correlation between $\delta^{37} \mathrm{Cl}$ and $\mathrm{SiO}_{2}$ (Figure 4A) and $\mathrm{Na}_{2} \mathrm{O}+\mathrm{K}_{2} \mathrm{O}$ (Figure 4B) illustrate that the different $\delta^{37} \mathrm{Cl}$ measured in Vulcano and Sukumoyama OHMIs compared to other OHMIs (Fig. 1) is not an analytical artefact. Indeed, OHMIs from these two samples have different $\mathrm{Cl}$ contents (>3000 ppm and $<1000 \mathrm{ppm}$, respectively) and major element compositions (Figure 2, SMs 3 to 5). Since calibrations were made with the same standards for all samples, and that OHMIs are corrected for IMF using their own major element compositions, it cannot be argued that the low $\delta^{37} \mathrm{Cl}$ values in the OHMIs are induced by analytical bias. The absence of correlation between $\delta^{37} \mathrm{Cl}$ and $\mathrm{SiO}_{2}$ and $\mathrm{Na}_{2} \mathrm{O}+\mathrm{K}_{2} \mathrm{O}$ within a sample (Figure 4) also suggests no fractionation of $\delta^{37} \mathrm{Cl}$ during magmatic evolution or due to variable degrees of melting.

We have also evaluated the effects of secondary processes (e.g, PEC, shrinkage bubble). Given that $\mathrm{Cl}$ is an ultra-trace element $(<1 \mathrm{ppm})$ in magmatic olivine (e.g., Urann et al., 2017), late crystallization of olivine on the wall of OHMIs should not strongly affect the $\mathrm{Cl}$ composition and $\mathrm{Cl}$ isotopes of OHMIs. This is verified by the absence of any relationship between $\delta^{37} \mathrm{Cl}$ and the extent of PEC. Shrinkage bubbles can contain volatile elements, mostly $\mathrm{CO}_{2}$ (e.g., Moore et al., 2015). So far, $\mathrm{Cl}$ content in such bubbles have not been determined. 
two or three OHMIS, but only one olivine contains two OHMIs with one containing a bubble and the other not (Aoba 3-1a and b). The one without bubbles contain 300 ppm less $\mathrm{Cl}$ than the one with a bubble, but the two OHMIs have similar $\delta^{37} \mathrm{Cl}$, within error $(-0.5 \pm 0.2$ and $0.7 \pm 0.2 \%$; SMs 3-4). Also, within a sample, the range of $\mathrm{Cl}$ content and $\delta^{37} \mathrm{Cl}$ are similar for OHMIs with or without a shrinkage bubble. We thus conclude that the presence of a shrinkage bubble does not affect $\mathrm{Cl}$ isotopes of OHMIs. This is further confirmed by the absence of a correlation between $\delta^{37} \mathrm{Cl}$ and $\mathrm{Cl} / \mathrm{K}_{2} \mathrm{O}$ (Figure 5), suggesting no $\mathrm{Cl}$ degassing syn- or post-entrapment. Also, $\mathrm{Cl}$ is not affected by diffusive re-equilibration through the host olivine (Bucholz et al., 2013). All this information suggests that the measured $\delta^{37} \mathrm{Cl}$ are representative of the melt in which the olivine grew.

\subsection{2. $\mathrm{Cl}$ and $\mathrm{O}$ isotope systematics}

In a plot of $\mathrm{Cl}$ isotopes compared to $\mathrm{O}$ isotopes, $\mathrm{AOC}$ and serpentinite fields are distinct from the field for sediments (Figure 6 and references in the caption). Oxygen isotope fractionation between hydrous minerals and fluids at high temperature is relatively small (for example, at $500^{\circ} \mathrm{C}, \sim-1.5 \%$ for serpentinite, amphibole; Zheng, 1993). Also, $\mathrm{Cl}$ isotopes in metamorphosed serpentinites and AOC are similar to those in fresh corresponding lithologies, suggesting that $\delta^{37} \mathrm{Cl}$ do not fractionate in fluids during the dehydration of mafic lithologies (Barnes et al., 2006; Bonifacie et al., 2008; John et al., 2011). Thus, the Cl-O isotope systematics in the OHMIs from each location have been compared to these end-members (Figure 6). In all the data taken together, $\mathrm{Cl}$ isotopes are negatively correlated with $\mathrm{O}$ isotopes, with the lowest $\delta^{37} \mathrm{Cl}$ observed in OHMIs with highest $\delta^{18} \mathrm{O}$ and vice versa. In detail, the OHMIs from St. Vincent and Iwate Volcano display a negative relationship, whereas no systematic could be described for those from Vulcano, Aoba and Sukumoyama. There is 
greater variation in $\delta^{18} \mathrm{O}$ data at low $\delta^{37} \mathrm{Cl}\left(<-1.6 \%\right.$ ). The lowest bulk $\delta^{37} \mathrm{Cl}$ (down to $-3 \%$ ) and the highest bulk $\delta^{18} \mathrm{O}(>9 \%$ ) have been observed in fresh sedimentary rocks, suggesting that the low $\delta^{37} \mathrm{Cl}(<-2 \%)$ associated with high $\delta^{18} \mathrm{O}(>7 \%)$ in the OHMIs do probably reflect the influence of fluids derived from sediments. The increased scatter of the OHMIs toward this end-member could be explained by the large range of subducted sediment compositions (carbonates, silicic sediments, shales, e.g., Bindeman, 2008 for a review).

High $\delta^{37} \mathrm{Cl}(>0.5 \%)$ associated with low $\delta^{18} \mathrm{O}(<5.5 \%)$ point toward an AOC or serpentinite end-member. In detail, the coupled $\delta^{37} \mathrm{Cl}$ and $\delta^{18} \mathrm{O}$ values reported for fresh serpentinite rocks formed at more than $100^{\circ} \mathrm{C}$ suggest that $\delta^{18} \mathrm{O}$ increases with $\delta^{37} \mathrm{Cl}$ in serpentinites (Bonifacie et al., 2008; Boschi et al., 2013). A fluid derived from fresh oceanic serpentinites would have a $\delta^{18} \mathrm{O}$ value $1.8 \%$ higher than the bulk rock it is derived from (Zheng, 1993) considering serpentinite dehydration at $\sim 680^{\circ} \mathrm{C}$ (antigorite breakdown, e.g., Trommsdorff et al., 1998). Thus, a fluid escaping a serpentinite with $\delta^{37} \mathrm{Cl}$ of $\sim 1 \%$ and $\delta^{18} \mathrm{O}$ from 4.5 to $7 \%$, based on the literature, will have a $\delta^{18} \mathrm{O}$ composition $>6.3 \%$. Such $\delta^{18} \mathrm{O}$ is too high to explain the highest $\delta^{37} \mathrm{Cl}$ end-member influencing the compositions of three out of four of the OHMIs with $\delta^{37} \mathrm{Cl}>0 \%$. Subducted serpentinites with higher $\delta^{37} \mathrm{Cl}$ have been reported (up to 2.4\%o, Barnes et al., 2006, 2013, 2014). In subducted serpentinite samples for which $\delta^{37} \mathrm{Cl}$ and $\delta^{18} \mathrm{O}$ have been determined, the same tendency of $\delta^{37} \mathrm{Cl}$ to increase with $\delta^{18} \mathrm{O}$ is observed (Barnes et al., 2014), leading to a similar conclusion as for the fresh oceanic serpentinites: a fluid escaping high $\delta^{37} \mathrm{Cl}$ subducted serpentinites might have a $\delta^{18} \mathrm{O}$ too high to explain the composition of OHMIs with $\delta^{37} \mathrm{Cl}>0 \%$. AOC, especially high temperature altered portions, have high $\delta^{37} \mathrm{Cl}$ (up to $+1.6 \%$; Barnes and Cisneros, 2012) and could have low $\delta^{18} \mathrm{O}$ (down to $3 \%$ for the bulk rock (Alt \& Bach, 2006); even as low as $0 \%$ for amphibole veins (Muehlenbachs, 1986)). If we assume a temperature of dehydration for 
amphibole of $\sim 500^{\circ} \mathrm{C}$ (blueschist - eclogite transition), a dehydration fluid from amphibole veins would have $\delta^{18} \mathrm{O} \sim 1.7 \%$ o higher than the dehydrating lithology/mineral (Zheng, 1993). Thus, local dehydration fluids from lower AOC could have $\delta^{18} \mathrm{O}$ values as low as $1.7 \%$, making amphibole-bearing AOC a more suitable candidate for the high $\delta^{37} \mathrm{Cl}-$ low $\delta^{18} \mathrm{O}$ endmember of the correlation. However, in detail, the Aoba OHMIs do not follow the general trend and might also point toward a serpentinite fluid end-member.

Following this reasoning, Vulcano and Sukumoyama OHMIs, with lower $\delta^{37} \mathrm{Cl}$ and higher $\delta^{18} \mathrm{O}$ than MORB (Sharp et al., 2007), possibly record the strongest influence from sediment derived fluids. St. Vincent and Iwate Volcano OHMIs, which have $\delta^{37} \mathrm{Cl}$ and $\delta^{18} \mathrm{O}$ both higher and lower compared to DMM, suggest that melts were influenced by a fluid possibly derived from the lower AOC and also some sediments. Aoba OHMIs also have both higher and lower $\delta^{37} \mathrm{Cl}$ and $\delta^{18} \mathrm{O}$ compared to DMM, suggesting influence from sediment fluids and AOC or serpentinite fluids.

It is important to note that contrary to the possible AOC and/or serpentinite end-member, which does not seem to have suffered fractionation of $\mathrm{Cl}$ isotopes during dehydration, as previously suggested (Barnes et al., 2006; Bonifacie et al., 2008; John et al., 2011; Schauble et al., 2003), the sediment end-member probably has fractionated at some point, as some OHMIs have $\delta^{37} \mathrm{Cl}$ values lower than the lowest $\delta^{37} \mathrm{Cl}$ reported for bulk sediments. This observation agrees with John et al. (2010), who suggest preferential loss of ${ }^{35} \mathrm{Cl}$ from sediments into pore fluids, even at high temperature, leads to enrichments in $\delta^{37} \mathrm{Cl}$ in recycled subducted marine sediments.

\subsection{3. $\mathrm{Cl}$ and $\mathrm{B}$ isotope systematics}

The distinction between AOC and serpentinite derived fluids is not unique due to their similar $\delta^{18} \mathrm{O}$ and $\delta^{37} \mathrm{Cl}$. Here, we investigate whether they can be distinguished in terms of 
their Cl-B isotope systematics (Figure 7). To date, $\mathrm{Cl}$ isotopes have not been coupled with $\mathrm{B}$ isotopes in the same rock samples. Fields for the different lithologies were thus assembled from different samples and different settings. $\mathrm{Cl}$ isotope values are given in SM 1. For B isotopes, sediment values are from Smith et al. (1997) and Ishikawa and Nakamura (1993); The AOC values are from Smith et al. (1995), and serpentinite values are from Boschi et al. (2013) and Vils et al. (2009). For reference, the MORB field is also plotted using the data for $\delta^{11} \mathrm{~B}$ from Chaussidon and Jambon (1994) and for $\delta^{37} \mathrm{Cl}$ from Sharp et al. (2007).

Boron isotopes fractionate strongly during dehydration, with ${ }^{11} \mathrm{~B}$ partitioning preferentially into the fluid phase (e.g., Peacok \& Hervig, 1999; Ishikawa \& Nakamura, 1994). Thus, B isotopes of the rock reservoirs cannot be directly compared to MI data. A simple open system Rayleigh distillation is used to estimate the theoretical composition of the dehydration fluids (Bouvier et al., 2010; Rose et al., 2001). For these calculations, B isotope fluid-rock partition coefficients of 3-5 \%o for serpentinites (Tenthorey and Hermann, 2004); and 5\% for AOC and sediments (You et al., 1996) were used.

There is no simple relationship between $\mathrm{Cl}$ and $\mathrm{B}$ isotopes for the OHMIs (Figure 7). Instead, for the whole dataset, different end-members are needed to explain the variations of $\delta^{11} \mathrm{~B}$ and $\delta^{37} \mathrm{Cl}$ in OHMIs. A first fluid end-member with $\delta^{11} \mathrm{~B}>12 \%$ and $\delta^{37} \mathrm{Cl}$ between -2 and $-0.5 \%$ could be described, most probably representing the influence of fluids derived from serpentinite dehydration. Indeed, amongst the three major $\mathrm{Cl}$ reservoirs shown in Figure 7, serpentinite rocks form the reservoir with the highest $\delta^{11} \mathrm{~B}$. Based on the Rayleigh distillation calculation, a fluid derived from the dehydration of serpentinites with an initial average $\delta^{11} \mathrm{~B}$ composition of $20 \%$ o (Figure 5) would have $\delta^{11} \mathrm{~B}$ down to $\sim 15 \%$ after $75 \%$ of B loss from serpentinite.

A second end-member can be described by higher $\delta^{37} \mathrm{Cl}(>1 \%)$ and lower $\delta^{11} \mathrm{~B}(<\sim 4 \%)$. High $\delta^{37} \mathrm{Cl}$ have been reported for AOC with a lithology containing amphiboles (Barnes and 
Cisneros, 2012) or for metamorphosed serpentinites (Barnes et al., 2014). Based on Figure 6,

409 OHMIs with $\delta^{37} \mathrm{Cl}>0 \%$ most likely record the influence of fluids released from amphibole

410 bearing- lower AOC. If an influence from an AOC dehydration fluid is assumed, with initial AOC average $\mathrm{B}$ isotopes composition of $3 \%$, $\delta^{11} \mathrm{~B}$ of $\sim 4 \%$ would suggest that a fluid escaping from an AOC lithology would have lost 50\% of B.

Finally, the last end-members most probably represent fluids from the subducted sediments, as suggested by Figure 6. Indeed, the lowest $\delta^{37} \mathrm{Cl}$ are measured in sedimentary rocks (Figure 1). Likewise, extremely low $\delta^{11} \mathrm{~B}(<-15 \%)$ measured in OHMIs are generally associated with the influence of fluids lost by dehydrated sediments - be they melts or fluids derived from such a lithology (e.g., Bouvier et al., 2010; Rose et al., 2001). Interestingly, Sukumoyama and Vulcano OHMIs seem to require two distinct sediment end-members, as in Figure 6 (thus OHMIs with similar $\delta^{37} \mathrm{Cl}$, but different $\delta^{18} \mathrm{O}$ and $\delta^{11} \mathrm{~B}$ ). This distinction could reflect different degrees of dehydration of the sediment lithology. However, due to the relatively small fractionation factor for $\mathrm{O}$ isotopes in the fluid at high temperature $\left(650^{\circ} \mathrm{C}\right.$, 0.4 and $1.8 \%$ for quartz and calcite; Zheng et al., 1993, 1999), different degrees of dehydration of similar sediment lithologies would not explain the different $\delta^{18} \mathrm{O}$ of Vulcano and Sukumoyama OHMIs. When compared to sediment bulk rock data, continental sediments have lower $\delta^{11} \mathrm{~B}$ than marine sediments (Ishikawa and Nakamura, 1993). Similarly, marine sediments have higher $\delta^{18} \mathrm{O}$ compared to continental sediments (see Bindeman et al., 2008 for a review). Simple Rayleigh distillation of marine sediment with an average initial composition of 5\% suggest $85 \%$ B loss to reach a fluid end-member with an average composition of $0 \%$. Similarly, an average composition of $-8 \%$ for continental sediments would lead to dehydration fluids with a composition of $-14 \%$ after $90 \%$ B loss. Whereas sediments being subducted in the Aeolian arc are mostly continental (dust from Sahara and clastic sediments from river Nile; Klaver et al., 2015), sediments subducted in the Izu-Bonin arc, where 
Sukumoyama is located, are mainly composed of marine sediments (ODP leg 1149; Plank et al., 2007) or clays (ODP leg 808; Plank and Langmuir, 1998), both of which have higher $\delta^{18} \mathrm{O}$ than continental sediments. Oxygen, $\mathrm{B}$ and $\mathrm{Cl}$ isotopes all point toward two distinct sediment end-members that are coherent with the tectonic settings of Vulcano and Sukumoyama. Boron isotopic variability within each sediment end-member could represent variable degrees of dehydration or variable compositions of the subducted sediments. John et al. (2010) suggested that dehydrated subducted marine sediments could have $\delta^{37} \mathrm{Cl}$ up to $+4 \%$ o (2\%o higher than highest measured values for fresh sediments, SM 1) due to $\mathrm{Cl}$ isotope fractionation during dehydration. Thus, a fluid derived from the dehydration of sediment with $\delta^{37} \mathrm{Cl}$ as low as $-5 \%$ o would suggest a similar, but opposite as in fluid and not in solid, fractionation than suggested by John et al. (2010) (2.5\% lower than lowest measured values for fresh sediments).

Combining $\mathrm{B}, \mathrm{O}$ and $\mathrm{Cl}$ isotopes might thus allow better identification of different $\mathrm{Cl}$ reservoirs (serpentinites vs. AOC; marine vs continental sediments) involved in magma genesis beneath arcs. Whereas the serpentinite reservoir cannot be easily identified in the $\mathrm{O}$ and $\mathrm{Cl}$ isotopes system, it can be distinguished from $\mathrm{AOC}$ in the $\mathrm{B}$ and $\mathrm{Cl}$ isotopes system. Similarly, influence of marine vs. terrigenous sediments seems to be more easily tracked in B and $\mathrm{Cl}$ isotope systems.

\subsubsection{Implications for the significance of $\delta^{37} \mathrm{Cl}$ variability}

Based on Figures 6 and 7, St. Vincent and Aoba mostly vary between AOC and serpentinite dehydration fluid end-members, suggesting a more pronounced influence from AOC and serpentinite fluids, compared to sediment fluids. Sediment fluids for St. Vincent can be marine and/or continental. The influence of three fluid end-members agrees with previous studies (Bouvier et al., 2008, 2010), and the suggested marine and continental sediments agrees with the sediment composition of the Barbados prism (Carpentier et al., 2008). Aoba 
OHMIs also seem to reflect the mixed influence of AOC and serpentinite fluids, and a marine fluid sediment component. Vulcano and Sukumoyama OHMIs record the strongest sediment influence, with a possible influence from serpentinite fluids to explain the scatter. Iwate Volcano OHMIs follow the Cl-O isotopes trend (Figure 4) suggesting the influence of both AOC and sediment fluids, in agreement with $\mathrm{Pb}$ isotope measurements on Iwate Volcano OHMIs (Rose-Koga et al., 2014). This is confirmed in Figure 7, with $\delta^{11} \mathrm{~B}$ suggesting an influence from marine sediments.

Overall, these observations, based on the Cl-O-B isotope systematics, are consistent with the geological settings of the volcanoes that have been sampled and suggest that variability within a sample reflects multiple reservoirs adding $\mathrm{Cl}$ to the mantle wedge. Inter-arc variations in $\delta^{37} \mathrm{Cl}$ most probably reflect global differences in the values for the main $\mathrm{Cl}$ reservoir (e.g., sediments vs. AOC and/or serpentinites).

\subsection{Bulk rock vs. OHMI Cl isotope differences}

New low $\delta^{37} \mathrm{Cl}(<-1.5 \%)$ are reported here, with Sukumoyama OHMIs having similar $\delta^{37} \mathrm{Cl}$ compositions compared to Vulcano OHMIs. Interestingly, bulk rock values of samples from the same arcs exist and can be compared with OHMI data. Even if bulk rock data are not from the same sample, nor from the same volcanoes, as the OHMIs in this study, nearby volcanoes from the same arc should have similar source(s) of $\mathrm{Cl}$ input. For the Aeolian arc, bulk rock data exist for Etna and Stromboli, both having similar $\delta^{37} \mathrm{Cl}(-0.96$ to $0.69 \%$ o for Stromboli and -0.7 to 0.1 for Etna; Liotta et al., 2017; Rizzo et al., 2013) despite their different magmatic histories (e.g., Tommasini et al., 2007). Also, as described in the introduction, Manzini et al. (2017) reported $\delta^{37} \mathrm{Cl}$ in OHMIs from Stromboli, with values significantly different (-3.2 to $-1.75 \%$ ) to Stromboli lavas, but similar to Vulcano OHMIs. We 
thus conclude that bulk rock data from nearby volcanoes (e.g., Stromboli for Vulcano, and Oshima and Niijima for Sukumoyama) could indeed be used to compare to OHMIs.

Bulk rock data are clearly different to our OHMI data, with a shift of up to $2 \%$ and $3.6 \%$ toward lower values for Vulcano and Sukumoyama OHMIs, respectively. As discussed in section 5.1.1., this could not be induced by analytical bias. Rather, the combination of negative $\delta^{37} \mathrm{Cl}$ and $\delta^{11} \mathrm{~B}$ associated with elevated $\delta^{18} \mathrm{O}$ suggest that the main source of $\mathrm{Cl}$ is from a fluid issued from sediments, as discussed above.

Fortin et al. (2017) showed that $\mathrm{Cl}$ isotopes could be fractionated by up to $5 \%$ by $\mathrm{Cl}$ diffusion during bubble growth, and potentially more in the case of diffusion not related to bubble growth (depending on time scale). As mentioned by these authors, fractionation by $\mathrm{Cl}$ diffusion during the formation of melt inclusions (i.e., via boundary layer entrapment) could not generate lower isotopic compositions, but instead should generate higher $\delta^{37} \mathrm{Cl}$ compared to the initial composition. In section 5.1.1., the migration of $\mathrm{Cl}$ into a shrinkage bubble was ruled out. If fractionation due to diffusion of $\mathrm{Cl}$ isotopes during shrinkage bubble growth within the OHMIs does occur, it will cause ${ }^{35} \mathrm{Cl}$ to preferentially enter the bubble, leading to $\delta^{37} \mathrm{Cl}$ progressively increasing in the melt (Fortin et al., 2017). In this case, OHMIs should have $\delta^{37} \mathrm{Cl}$ compositions higher than bulk rock, whereas we have observed the opposite. As no correlation has been observed between $\mathrm{Cl}$ or $\mathrm{Cl} / \mathrm{K}_{2} \mathrm{O}$ and $\delta^{37} \mathrm{Cl}$ (Figure 5), the lower $\delta^{37} \mathrm{Cl}$ values measured in Vulcano and Sumukoyama OHMIs compared to respective bulk rocks probably do not represent degassing melts. On the contrary, bulk rocks have often suffered some volatile degassing. For example, the Stromboli OHMIs measured for $\delta^{37} \mathrm{Cl}$ have $\mathrm{Cl}$ contents from 0.14 to $0.46 \mathrm{wt} \%$ (Manzini et al., 2017), whereas bulk rocks only contain 0.03 to $0.08 \mathrm{wt} \%$ (Liotta et al., 2017). Assuming fractionation due to diffusion of $\mathrm{Cl}$ isotopes during bubble growth in the magma (as opposed to shrinkage bubble growth in OHMIs), gases enriched in ${ }^{35} \mathrm{Cl}$ could be created. This will thus create low $\delta^{37} \mathrm{Cl}$ gases and a magma 
505 with $\delta^{37} \mathrm{Cl}$ increasing with the increase of degassing. Interestingly, low $\delta^{37} \mathrm{Cl}$ has been measured in Hakone (northern part of Izu-Bonin arc, down to -5.41\%; Barnes et al., 2008) and Stromboli gases (down to -2.2\%o; Liotta et al., 2017). OHMIs from Sukumoyama and Vulcano could thus represent relatively primary undegassed melt, whereas the bulk rocks record $\mathrm{Cl}$ loss during degassing, enriching the melt in ${ }^{37} \mathrm{Cl}$ due to diffusive fractionation during bubble growth. In that case, the bulk rocks lose the original $\delta^{37} \mathrm{Cl}$ signature of the source of the $\mathrm{Cl}$ input.

\section{Conclusions}

This study expands the dataset of $\mathrm{Cl}$ isotopes in OHMIs from arc settings and is the first coupling $\delta^{37} \mathrm{Cl}$ with two other isotopic systems in OHMIs. This dataset suggests that $\mathrm{Cl}$ isotopes variation in OHMIs within a single sample most probably record $\mathrm{Cl}$ input from different $\mathrm{Cl}$ reservoirs, rather than heterogeneity from a single reservoir. Inter-arc variability in $\delta^{37} \mathrm{Cl}$ might reflect differences in the main $\mathrm{Cl}$ reservoirs (e.g., larger influences of sediments in some arcs).

Indirect comparison of OHMI data from Vulcano and Sukumoyama and bulk rock data from the same arc reveal large (2 to $4 \%$ ) differences, with OHMIs having lower $\delta^{37} \mathrm{Cl}$ than bulk rocks. This difference most probably reflects diffusive fractionation of $\mathrm{Cl}$ isotopes during degassing of the lavas. OHMIs have relatively primary compositions whereas the bulk lavas have lost the original $\delta^{37} \mathrm{Cl}$ signature during degassing. This conclusion is supported by some low $\left(<0 \%\right.$ o $\delta^{37} \mathrm{Cl}$ gases measured at volcanoes in both arcs.

Chlorine isotope measurements by SIMS in MIs could thus provide valuable and unique access to relatively primary (undegassed) $\delta^{37} \mathrm{Cl}$ compositions. Better constraints on the source of $\mathrm{Cl}$ is important to better understand the behavior or $\mathrm{Cl}$ in different contexts and ultimately, refine the $\mathrm{Cl}$ budget. 


\section{Acknowledgments}

531 Research was supported by the KIP-6 PCI grant CASA to LPB. EFR-K acknowledges the 532 French Government Laboratory of Excellence initiative $n^{\circ}$ ANR-10- LABEX-0006. The 533 authors would like to thank Nicole Métrich for thoughtful comments, Janne Koornneef, two 534 anonymous reviewers and the editor, Frederic Moynier, for the helpful reviews and 535 suggestions.

\section{References}

538

539

540

541

542

543

544

545

546

547

548

549

550

551

552

Aiuppa, A., Baker, D.R., Webster, J.D., 2009. Halogens in volcanic systems. Chem. Geol. 263, 1-18. https://doi.org/10.1016/j.chemgeo.2008.10.005

Alt, J.C., 2003. Stable isotopic composition of upper oceanic crust formed at a fast spreading ridge, ODP Site 801. Geochemistry, Geophys. Geosystems 4, 1-11. https://doi.org/10.1029/2002GC000400

Alt, J.C., Bach, W., 2006. Oxygen isotope composition of a section of lower oceanic crust, ODP Hole 735B. Geochemistry, Geophys. Geosystems 7. https://doi.org/10.1029/2006GC001385

Barnes, J.D., Beltrando, M., Lee, C.T.A., Cisneros, M., Loewy, S., Chin, E., 2014. Geochemistry of Alpine serpentinites from rifting to subduction: A view across paleogeographic domains and metamorphic grade. Chem. Geol. 389, 29-47. https://doi.org/10.1016/j.chemgeo.2014.09.012

Barnes, J.D., Cisneros, M., 2012. Mineralogical control on the chlorine isotope composition of altered oceanic crust. Chem. Geol. 326-327, 51-60. https://doi.org/10.1016/j.chemgeo.2012.07.022

Barnes, J.D., Selverstone, J., Sharp, Z.D., 2006. Chlorine isotope chemistry of serpentinites from Elba, Italy, as an indicator of fluid source and subsequent tectonic history. Geochemistry, Geophys. Geosystems 7. https://doi.org/10.1029/2006GC001296 
Barnes, J.D., Sharp, Z.D., Fischer, T.P., 2008. Chlorine isotope variations across the Izu-BoninMariana arc. Geology 36, 883. https://doi.org/10.1130/G25182A.1

Barnes, J.D., Sharp, Z.D., Fischer, T.P., Hilton, D.R., Carr, M.J., 2009. Chlorine isotope variations along the Central American volcanic front and back arc. Geochemistry, Geophys. Geosystems 10, n/a-n/a. https://doi.org/10.1029/2009GC002587

Barnes, J.D., Straub, S.M., 2010. Chorine stable isotope variations in Izu Bonin tephra: Implications for serpentinite subduction. Chem. Geol. 272, 62-74. https://doi.org/10.1016/j.chemgeo.2010.02.005

Bindeman, I., 2008. Oxygen Isotopes in Mantle and Crustal Magmas as Revealed by Single Crystal Analysis. Rev. Mineral. Geochemistry 69, 445-478. https://doi.org/10.2138/rmg.2008.69.12

Bonifacie, M., Busigny, V., Mével, C., Philippot, P., Agrinier, P., Jendrzejewski, N., Scambelluri, M., Javoy, M., 2008. Chlorine isotopic composition in seafloor serpentinites and high-pressure metaperidotites. Insights into oceanic serpentinization and subduction processes. Geochim. Cosmochim. Acta 72, 126-139. https://doi.org/10.1016/j.gca.2007.10.010

Boschi, C., Bonatti, E., Ligi, M., Brunelli, D., Cipriani, A., Dallai, L., D’Orazio, M., Früh-Green, G.L., Tonarini, S., Barnes, J.D., Bedini, R.M., 2013. Serpentinization of mantle peridotites along an uplifted lithospheric section, mid atlantic ridge at $11^{\circ} \mathrm{N}$. Lithos 178, 3-23. https://doi.org/10.1016/j.lithos.2013.06.003

Bouvier, A.-S., Metrich, N., Deloule, E., 2008. Slab-Derived Fluids in the Magma Sources of St. Vincent (Lesser Antilles Arc): Volatile and Light Element Imprints. J. Petrol. 49, 1427-1448. https://doi.org/10.1093/petrology/egn031

Bouvier, A.-S., Deloule, E., Metrich, N., 2010. Fluid Inputs to Magma Sources of St. Vincent and Grenada (Lesser Antilles): New Insights from Trace Elements in Olivine-hosted Melt Inclusions. J. Petrol. 51, 1597-1615. https://doi.org/10.1093/petrology/egq031

Bucholz, C.E., Gaetani, G. a., Behn, M.D., Shimizu, N., 2013. Post-entrapment modification of volatiles and oxygen fugacity in olivine-hosted melt inclusions. Earth Planet. Sci. Lett. 374, 145- 
580

581

582

583

584

585

586

587

588

589

590

591

592

593

594

595

596

597

598

599

600

601

602

603

604

Carpentier, M., Chauvel, C., Mattielli, N., 2008. Pb-Nd isotopic constraints on sedimentary input into the Lesser Antilles arc system. Earth Planet. Sci. Lett. 272, 199-211. https://doi.org/10.1016/j.eps1.2008.04.036

Chaussidon, M., Jambon, A., 1994. Boron content and isotopic composition of oceanic basalts: Geochemical and cosmochemical implications. Earth Planet. Sci. Lett. 121, 277-291.

Fortin, M.-A., Watson, E.B., Stern, R., 2017. The isotope mass effect on chlorine diffusion in dacite melt, with implications for fractionation during bubble growth. Earth Planet. Sci. Lett. 480, 15-24. https://doi.org/https://doi.org/10.1016/j.epsl.2017.09.042

Ishikawa, T., Nakamura, E., 1993. Boron isotope systematics of marine sediments. Earth Planet. Sci. Lett. 117, 567-580. https://doi.org/10.1016/0012-821X(93)90103-G

John, T., Scambelluri, M., Frische, M., Barnes, J.D., Bach, W., 2011. Dehydration of subducting serpentinite: Implications for halogen mobility in subduction zones and the deep halogen cycle. Earth Planet. Sci. Lett. 308, 65-76. https://doi.org/10.1016/j.eps1.2011.05.038

John, T., Scherer, E.E., Schenk, V., Herms, P., Halama, R., Garbe-Schönberg, D., 2010. Subducted seamounts in an eclogite-facies ophiolite sequence: the Andean Raspas Complex, SW Ecuador. Contrib. to Mineral. Petrol. 159, 265-284. https://doi.org/10.1007/s00410-009-0427-0

Klaver, M., Djuly, T., de Graaf, S., Sakes, A., Wijbrans, J., Davies, G., Vroon, P., 2015. Temporal and spatial variations in provenance of Eastern Mediterranean Sea sediments: Implications for Aegean and Aeolian arc volcanism. Geochim. Cosmochim. Acta 153, 149-168. https://doi.org/10.1016/j.gca.2015.01.007

Liebscher, A., Barnes, J.D., Sharp, Z., 2006. Chlorine isotope vapor-liquid fractionation during experimental fluid-phase separation at $400{ }^{\circ} \mathrm{C} / 23 \mathrm{MPa}$ to $450{ }^{\circ} \mathrm{C} / 42 \mathrm{MPa}$. Chem. Geol. 234, 340345. https://doi.org/10.1016/j.chemgeo.2006.04.009

Liotta, M., Rizzo, A.L., Barnes, J.D., D’Auria, L., Martelli, M., Bobrowski, N., Wittmer, J., 2017. Chlorine isotope composition of volcanic rocks and gases at Stromboli volcano (Aeolian Islands, 
Italy): Inferences on magmatic degassing prior to 2014 eruption. J. Volcanol. Geotherm. Res. 336, 168-178. https://doi.org/https://doi.org/10.1016/j.jvolgeores.2017.02.018

Manzini, M., Bouvier, A.-S., Barnes, J.D., Bonifacie, M., Rose-Koga, E.F., Ulmer, P., Métrich, N., Bardoux, G., Williams, J., Layne, G.D., Straub, S., Baumgartner, L.P., John, T., 2017. SIMS chlorine isotope analyses in melt inclusions from arc settings. Chem. Geol. 449. https://doi.org/10.1016/j.chemgeo.2016.12.002

Mather, T. a., Witt, M.L.I., Pyle, D.M., Quayle, B.M., Aiuppa, a., Bagnato, E., Martin, R.S., Sims, K.W.W., Edmonds, M., Sutton, a. J., Ilyinskaya, E., 2012. Halogens and trace metal emissions from the ongoing 2008 summit eruption of Kīlauea volcano, Hawai i. Geochim. Cosmochim. Acta 83, 292-323. https://doi.org/10.1016/j.gca.2011.11.029

Métrich, N., Deloule, E., 2014. Water content, $\delta \mathrm{D}$ and $\delta 11 \mathrm{~B}$ tracking in the Vanuatu arc magmas (Aoba Island): Insights from olivine-hosted melt inclusions. Lithos 206-207, 400-408. https://doi.org/10.1016/j.lithos.2014.08.011

Moore, L.R., Gazel, E., Tuohy, R., Lloyd, A.S., Esposito, R., Steele-MacInnis, M., Hauri, E.H., Wallace, P.J., Plank, T., Bodnar, R.J., 2015. Bubbles matter: An assessment of the contribution of vapor bubbles to melt inclusion volatile budgets. Am. Mineral. 100, 806-823.

Muehlenbachs, K., 1986. Alteration of the oceanic crust and the $18 \mathrm{O}$ history of seawater. Rev. Mineral. Geochemistry 16, 425-444.

Nichols, A.R.L., Wysoczanski, R.J., Tani, K., Tamura, Y., Baker, J.A., Tatsumi, Y., 2012. Melt inclusions reveal geochemical cross-arc variations and diversity within magma chambers feeding the Higashi-Izu Monogenetic Volcano Field, Izu Peninsula, Japan. Geochemistry, Geophys. Geosystems 13, 1-28. https://doi.org/10.1029/2012GC004222Peacock, S.M., Hervig, R.L., 1999. Boron isotopic composition of subduction-zone metamorphic rocks. Chem. Geol. 160, 281-290.

Peccerillo, A., De Astis, G., Faraone, D., Forni, F., Frezzotti, M.L., 2013. Chapter 15 Compositional variations of magmas in the Aeolian arc: implications for petrogenesis and geodynamics. Geol. Soc. London, Mem. 37, 491-510. https://doi.org/10.1144/M37.15 
Plank, T., Kelley, K.A., Murray, R.W., Stern, L.Q., 2007. Chemical composition of sediments subducting at the Izu-Bonin trench. Geochemistry, Geophys. Geosystems 8, 1-16. https://doi.org/10.1029/2006GC001444

Plank, T., Langmuir, C.H., 1998. The chemical composition of subducting sediment and its consequences for the crust and mantle. Chem. Geol. 145, 325-394.

Rizzo, A.L., Caracausi, A., Liotta, M., Paonita, A., Barnes, J.D., Corsaro, R. a., Martelli, M., 2013. Chlorine isotope composition of volcanic gases and rocks at Mount Etna (Italy) and inferences on the local mantle source. Earth Planet. Sci. Lett. 371-372, 134-142. https://doi.org/10.1016/j.eps1.2013.04.004

Rose, E.F., Shimizu, N., Layne, G.D., Grove, T.L., 2001. Melt production beneath Mt. Shasta from boron data in primitive melt inclusions. Science 293, 281-3. https://doi.org/10.1126/science.1059663

Rose-Koga, E.F., Koga, K.T., Hamada, M., Hélouis, T., Whitehouse, M.J., Shimizu, N., 2014. Volatile ( $\mathrm{F}$ and $\mathrm{Cl}$ ) concentrations in Iwate olivine-hosted melt inclusions indicating low-temperature subduction. Earth, Planets Sp. 66, 81. https://doi.org/10.1186/1880-5981-66-81

Rosner, M., Wiedenbeck, M., Ludwig, T., 2008. Composition-Induced Variations in SIMS Instrumental Mass Fractionation during Boron Isotope Ratio Measurements of Silicate Glasses. Geostand. Geoanalytical Res. 32, 27-38. https://doi.org/10.1111/j.1751-908X.2008.00875.x

Schauble, E.A., Rossman, G.R., Taylor, H.P., J., 2003. Theoretical estimates of equilibrium chlorineisotope fractionations. Geochim. Cosmochim. Acta 67, 3267-3281. https://doi.org/10.1016/S00167037(00)01375-3

Sharp, Z.D., Barnes, J.D., Brearley, a J., Chaussidon, M., Fischer, T.P., Kamenetsky, V.S., 2007. Chlorine isotope homogeneity of the mantle, crust and carbonaceous chondrites. Nature 446, $1062-$ 1065. https://doi.org/10.1038/nature05748

Smith, H.J., Leeman, W.P., Davidson, J., Spivack, A.J., 1997. The B isotopic composition of arc lavas from Martinique, Lesser Antilles. Earth Planet. Sci. Lett. 146, 303-314. 
Smith, H.J., Spivack, A.J., Staudigel, H., Hart, S.R., 1995. The boron isotopic composition of altered oceanic crust. Chem. Geol. 126, 119-135.

Sorbadere, F., Schiano, P., Métrich, N., Garaebiti, E., 2011. Insights into the origin of primitive silicaundersaturated arc magmas of Aoba volcano (Vanuatu arc). Contrib. to Mineral. Petrol. 162, 9951009. https://doi.org/10.1007/s00410-011-0636-1

Tenthorey, E., Hermann, J., 2004. Composition of fluids during serpentinite breakdown in subduction zones: Evidence for limited boron mobility. Geology 32, 865-868.

Tommasini, S., Heumann, A., Avanzinelli, R., Francalanci, L., 2007. The Fate of High-Angle Dipping Slabs in the Subduction Factory: an Integrated Trace Element and Radiogenic Isotope (U, Th, Sr, $\mathrm{Nd}, \mathrm{Pb}$ ) Study of Stromboli Volcano, Aeolian Arc, Italy. J. Petrol. 48, 2407-2430.

Trommsdorff, V., Sánchez-Vizcaíno, V.L., Gómez-Pugnaire, M.T., Müntener, O., 1998. High pressure breakdown of antigorite to spinifex-textured olivine and orthopyroxene, SE Spain. Contrib. to Mineral. Petrol. 132, 139-148. https://doi.org/10.1007/s004100050412

Urann, B.M., Le Roux, V., Hammond, K., Marschall, H.R., Lee, C.-T.A., Monteleone, B.D., 2017. Fluorine and chlorine in mantle minerals and the halogen budget of the Earth's mantle. Contrib. to Mineral. Petrol. 172, 51. https://doi.org/10.1007/s00410-017-1368-7

Vils, F., Tonarini, S., Kalt, A., Seitz, H.-M., 2009. Boron, lithium and strontium isotopes as tracers of seawater-serpentinite interaction at Mid-Atlantic ridge, ODP Leg 209. Earth Planet. Sci. Lett. 286, 414-425. https://doi.org/10.1016/j.eps1.2009.07.005

You, C., Spivack, A.J., Gieskes, J.M., Martin, J.B., Davisson, M.L., 1996. Boron contents and isotopic compositions in pore waters : a new approach to determine temperature induced artifactsgeochemical implications 129, 351-361.

Zheng, Y.F., 1993. Calculation of oxygen isotope fractionation in hydroxyl-bearing silicates. Earth Planet. Sci. Lett. 120, 247-263. https://doi.org/10.1016/0012-821X(93)90243-3

Zheng, Y.-F., Satir, M., Metz, P., Sharp, Z.D., 1999. Oxygen isotope exchange processes and 
683 disequilibrium between calcite and forsterite in an experimental $\mathrm{C}-\mathrm{O}-\mathrm{H}$ fluid. Geochim. 684 Cosmochim. Acta 63, 1781-1786.

685 


\section{Captions:}

687 Figure 1: Compilation of published $\delta^{37} \mathrm{Cl}$ for terrestrial bulk rocks and olivine-hosted melt inclusions (OHMIs). Sukumoyama and Iwate Volcano OHMIs are new data, the remaining are published data. A summary of the database can be found in SM 1, with all the associated references. OHMIs are plotted using symbols, whereas bulk rocks are represented with bars. Sediments and serpentinite bulk rocks are plotted with dark colors representing fresh rocks, and light colors metamorphic rocks.

Figure 2: $\mathrm{SiO}_{2}$ compared to total alkalis $\left(\mathrm{Na}_{2} \mathrm{O}+\mathrm{K}_{2} \mathrm{O}\right)$ (TAS diagram) for OHMIs of St. Vincent (squares), Aeolian islands (triangles), Aoba (diamonds), Sukumoyama (yellow circles) and Iwate (brown circles). The OHMIs have basanitic to basaltic compositions.

Figure 3: $\mathrm{SiO}_{2}$ compared to $\mathrm{Cl}$ content in the studied OHMIs. Symbols as in Figure 2. No variation of $\mathrm{Cl}$ content with increasing $\mathrm{SiO}_{2}$ is observed, suggesting $\mathrm{Cl}$ is not degassing during OHMIs entrapment.

Figure 4: Chlorine isotopes compared to $\mathrm{SiO}_{2}(\mathrm{~A})$ and $\mathrm{Na}_{2} \mathrm{O}+\mathrm{K}_{2} \mathrm{O}$ (B) in the OHMIs. No correlation between $\delta^{37} \mathrm{Cl}$ and the major elements are seen, proving that the matrix effect has been corrected. Also, the absence of any correlation suggests that $\mathrm{Cl}$ isotopes are not affected by extent of magmatic evolution.

Figure 5: Chlorine isotopes compared to $\mathrm{Cl} / \mathrm{K}_{2} \mathrm{O}$ ratios. The absence of correlation between $\delta^{37} \mathrm{Cl}$ and $\mathrm{Cl} / \mathrm{K}_{2} \mathrm{O}$ supports the absence of $\mathrm{Cl}$ degassing at the time of entrapment. Thus, the variation of $\delta^{37} \mathrm{Cl}$ in the OHMIs cannot be linked to degassing.

Figure 6: $\mathrm{O}$ isotopes compared to $\mathrm{Cl}$ isotopes in St. Vincent (squares), Aeolian islands (triangles), Aoba (diamonds), Sukumoyama (yellow circles) and Iwate (brown circles) OHMIs. All OHMIs define a negative relationship between $\delta^{37} \mathrm{Cl}$ and $\delta^{18} \mathrm{O}$. Sukumoyama and Aeolian OHMIs record the strongest influence from sediment fluids, whereas St. Vincent and Iwate Volcano record fluids derived from the dehydration of both AOC and sediments. Aoba also reflect influences from sediment fluids, and either AOC or serpentinite fluids. Fields for sediments, $\mathrm{AOC}$ and serpentinites are based on bulk rock data. Bulk rock $\mathrm{O}$ and $\mathrm{Cl}$ isotope data were obtained on the same samples only for oceanic serpentinites. $\mathrm{Cl}$ isotope data are from the same references as in Figure 1 and SM 1. Oxygen isotope data for AOC are from Alt (2003) and Alt \& Bach (2006). Only fresh oceanic serpentinites have been reported here (data for $\delta^{18} \mathrm{O}$ are from Bonifacie et al. (2008) and Boschi et al. (2013)). Fresh sedimentary rock $\delta^{18} \mathrm{O}$ data are from the compilation of Bindeman (2008). 
713 Figure 7: B isotopes compared to $\mathrm{Cl}$ isotopes. Symbols are as in Figure 5. For comparison, different reservoirs

714

715

716

717

718

719

720

721

722

\section{Supplementary material}

SM2: SIMS calibrations

726

727

728

729

730

731

732 continental sediments. have been plotted (see text for references). As for Figure 4, only fresh sediments and serpentinites have been reported. Reservoirs defined by dashed lines are a compilation of data in which none of the samples have combined $\delta^{11} \mathrm{~B}$ and $\delta^{37} \mathrm{Cl}$ measurements. OHMIs suggest the influence of four different fluid end-members, one each for AOC and serpentinites, and two distinct end-members for sediments, one for marine and one for

Table 1: $\mathrm{B}, \mathrm{O}$ and $\mathrm{Cl}$ isotopes in OHMIs

SM1: Database for $\mathrm{Cl}$ isotopes in terrestrial bulk rocks and OHMIs

SM3: Summary of major element and stable isotopes of OHMIs used in Manzini et al. (2017)

SM4: Summary of major elements and stable isotopes of OHMIs from Iwate Volcano and Sukumoyama

SM5: Comparison of major element compositions of OHMIs and whole rocks. 


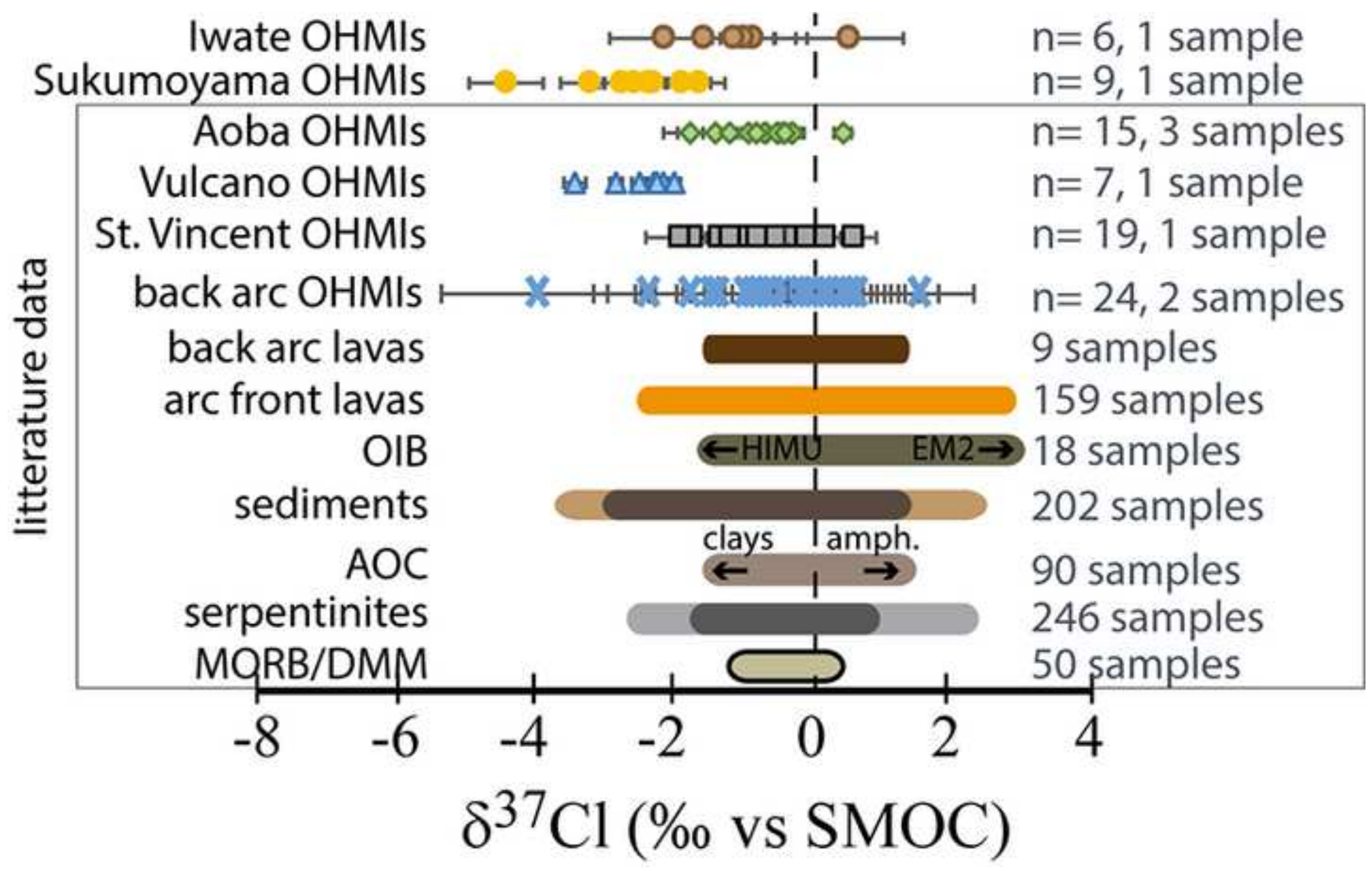




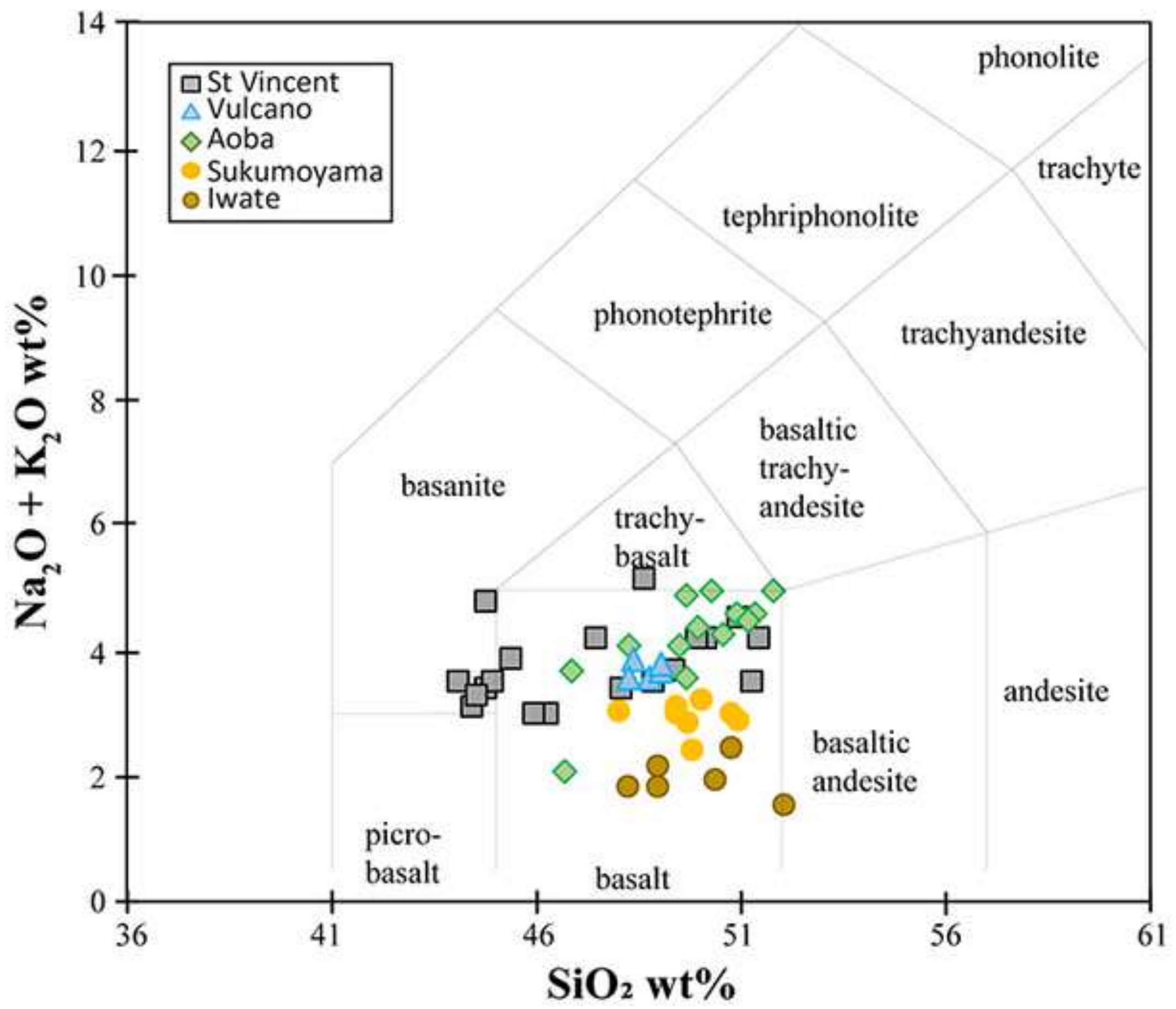




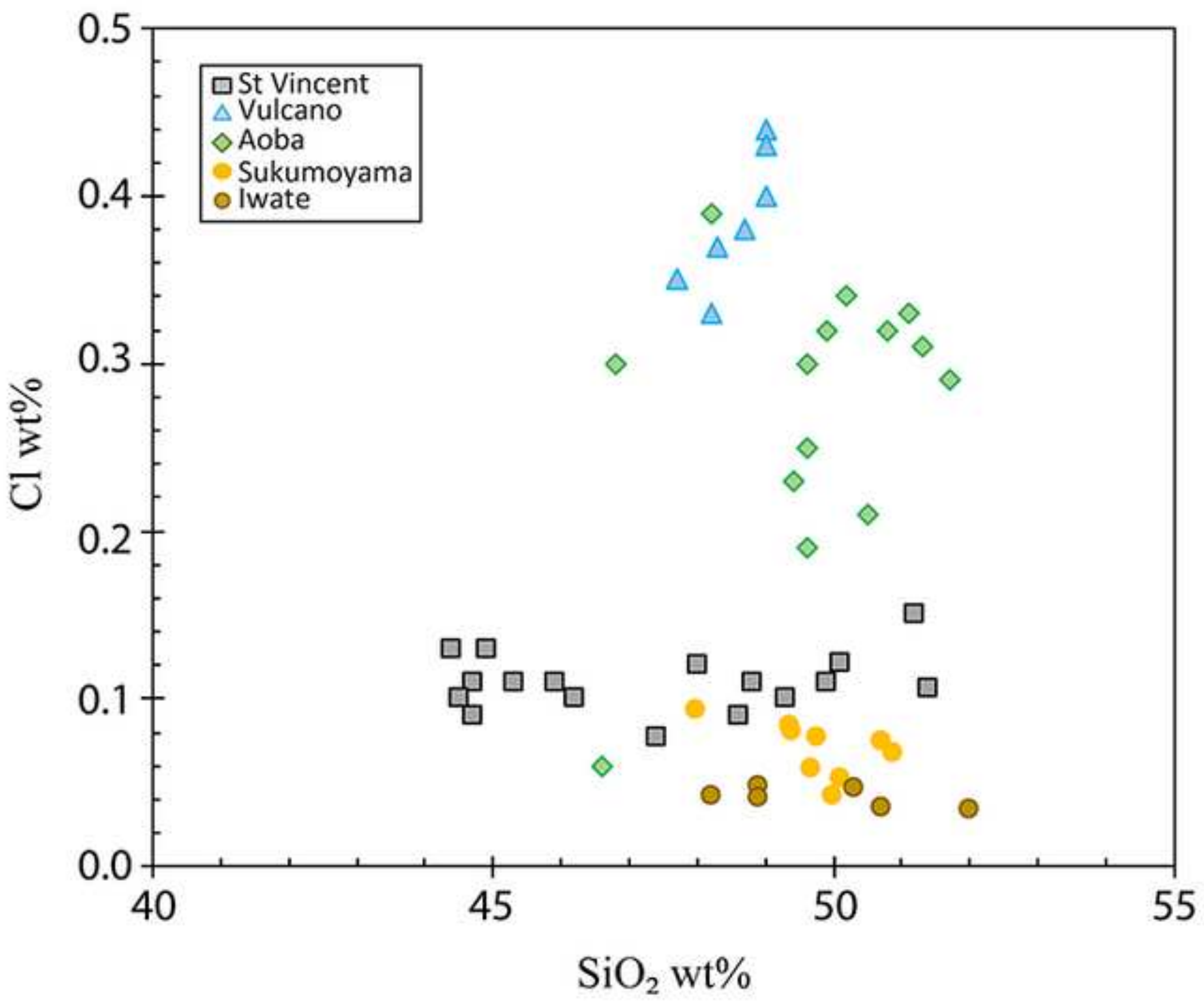




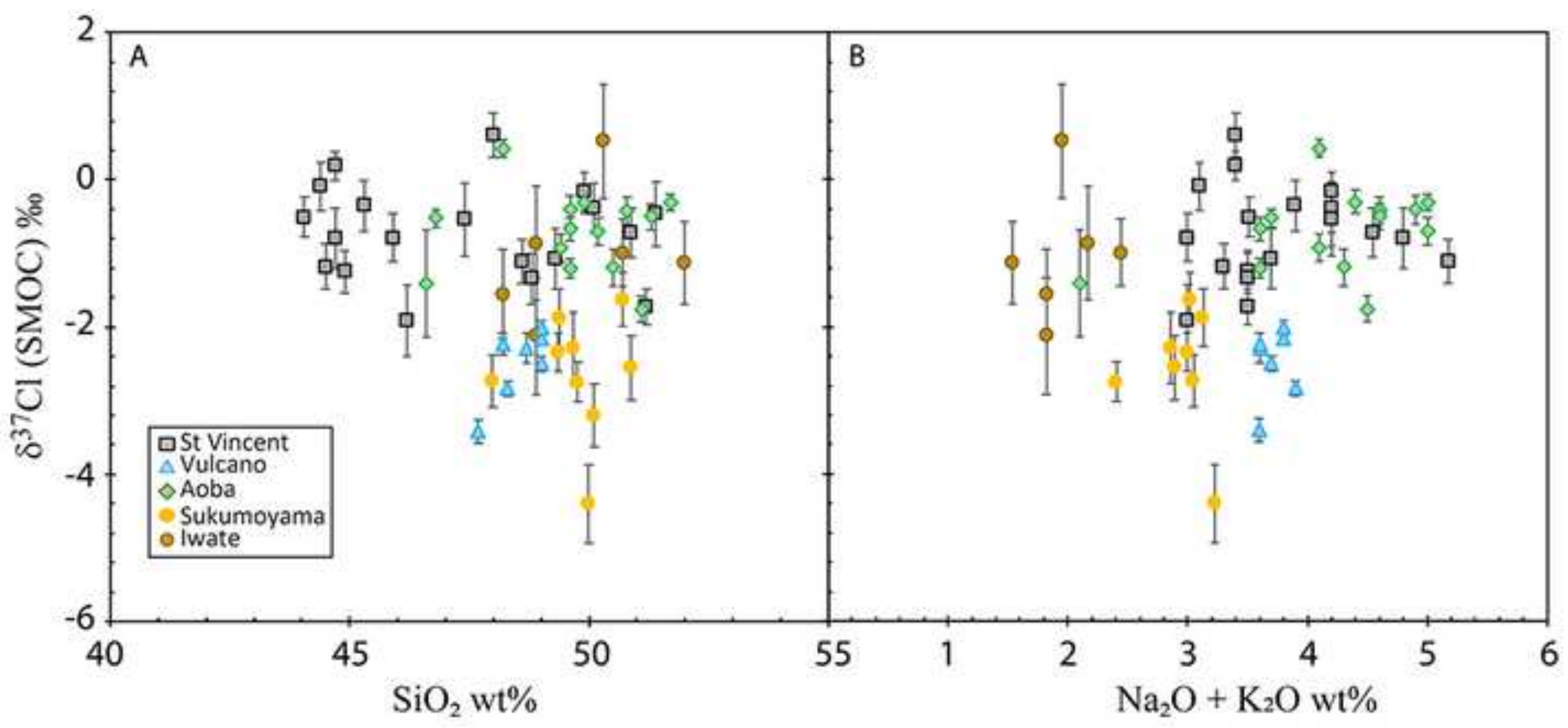




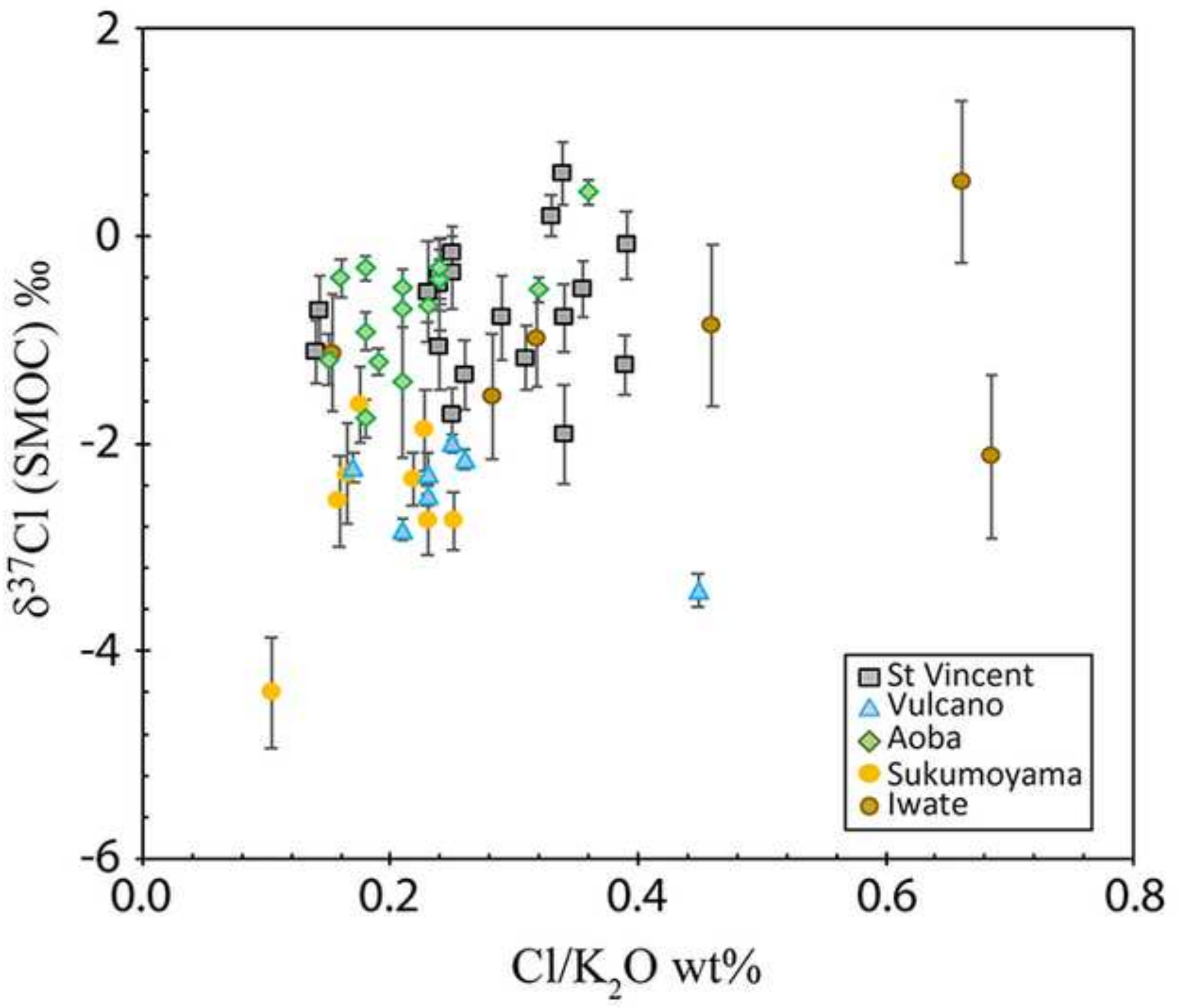




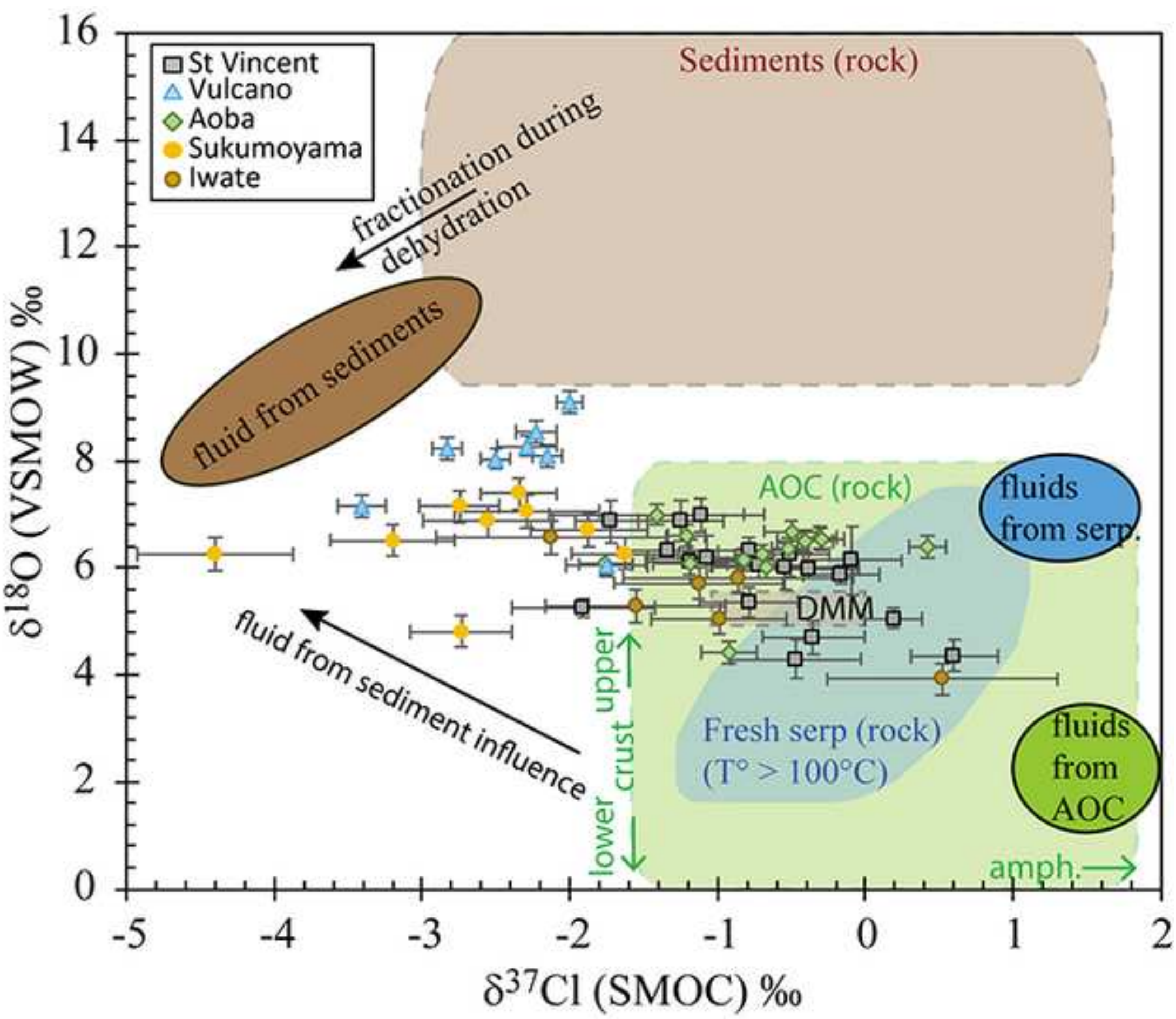




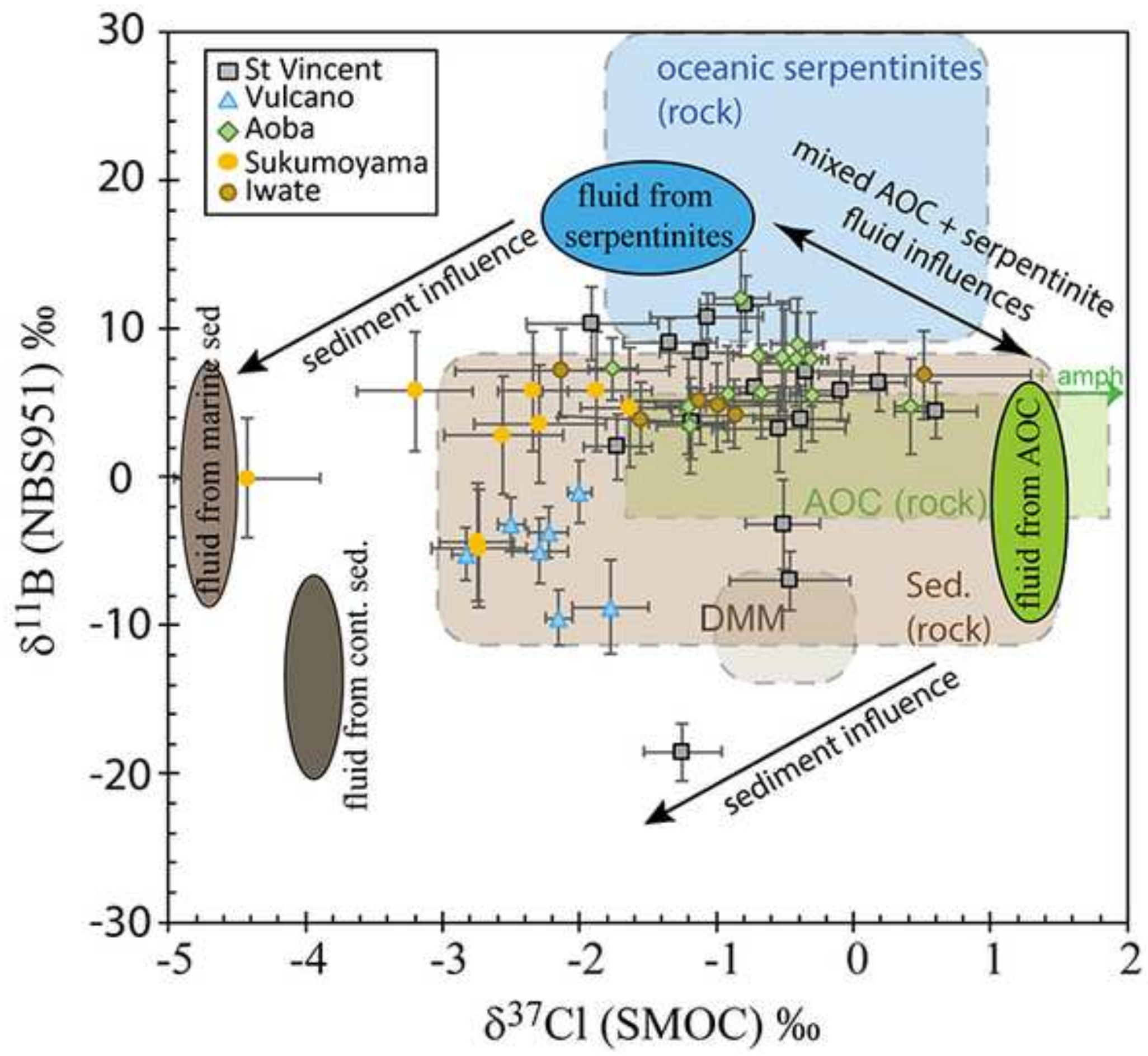


Figure (high-resolution) 1
Click here to download Figure (high-resolution): Fig1.tif

Click here to download Figure (high-resolution): Figitif

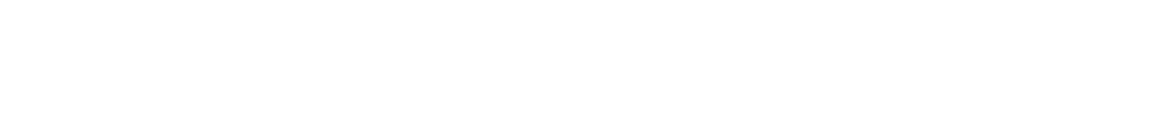

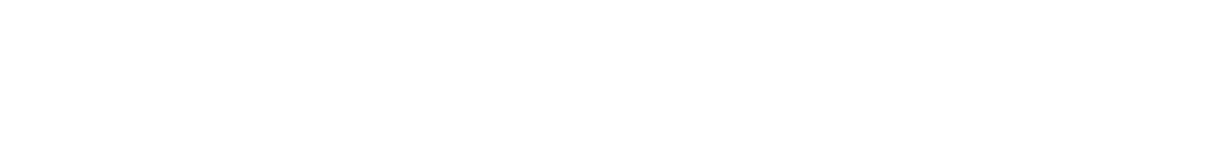

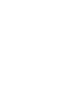
(1) (1) (1) (1) (1) (1) (1) (1) (1) . . . . . . . . 
Figure (high-resolution) 2
Click here to download Figure (high-resolution): Fig2_TAS.tif

Figure (high-resolution) 2
Click here to download Figure (high-resolution): Fig2_TAS.tif

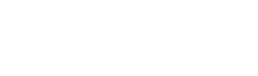

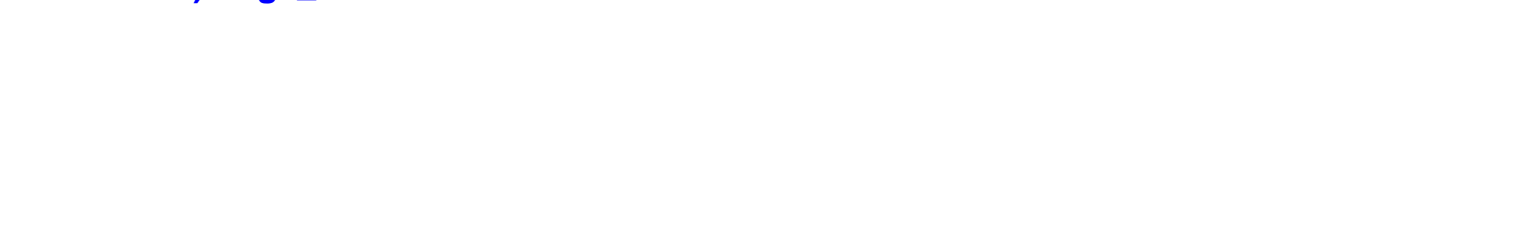


Figure (high-resolution) 3
Click here to download Figure (high-resolution): Fig3_Cl-vs-SiO2.ti

Figure (high-resolution) 3
Click here to download Figure (high-resolution): Fig3_Cl-vs-SiO2.tif

\begin{abstract}
(1)
\end{abstract} if (2) $\sqrt{10}$

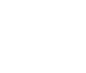

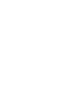
$\sqrt{2}$

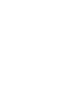
(a) 

Figure (high-resolution) 4
Click here to download Fig Figure (high-resolution) 4
Click here to download Figure (high-resolution): Fig4_d37Cl-vs-SiO2\&-vs-alcalins.tif

Clit

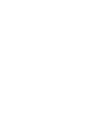

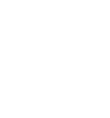
(a)

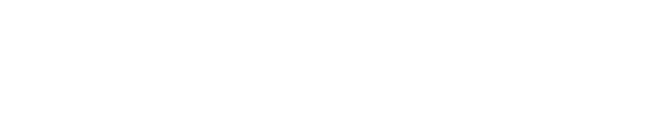

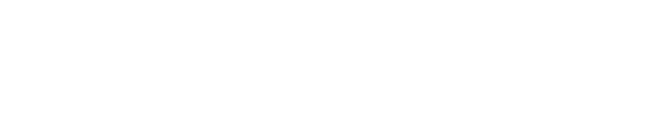
lick here to download Figure (high-resolution -

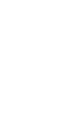

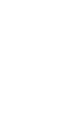

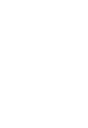
. . . .

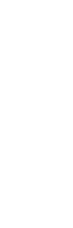

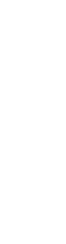
(1) (1) (1) (1) (1) (1) (1) (1) (1)

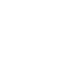

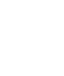

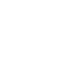
(1) 
Figure (high-resolution) 5

Click here to download Figure (high-resolution): Fig5_d37Cl-vs-Cl-K2O.tif

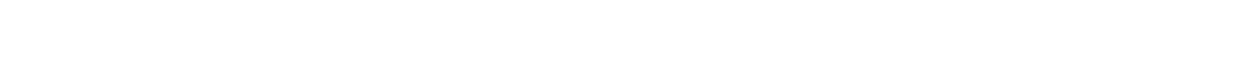

Click here to download Figure (high-resolution): Figs_d37Cl-vs-Cl-K2O.tif

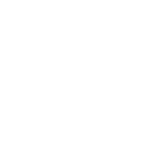

. (1)

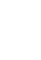

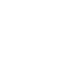
(1)

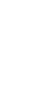
(1) (1)

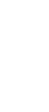
. .

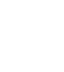

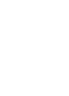

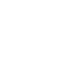

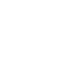

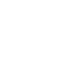

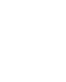

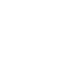

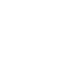

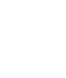

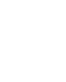

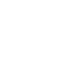

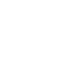

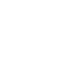

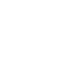

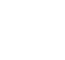



Figure (high-resolution) 6
Click here to download Figure (high-resolution): Fig6_new.tif

Figure (high-resolution) 6
Click here to download Figure (high-resolution): Fig6_new.tif

(1)

(1)

(1)

(1)

(1)

(1)

(1)

(1)

(1)

(1)

.

.

.

.

.

.

.

.

.

.

.

.

.

.

.

.

.

.

. 
Figure (high-resolution) 7
Click here to download Figure (high-resolution): Fig7_new.tif

Figure (high-resolution) 7
Click here to download Figure (high-resolution): Fig7_new.tif

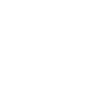

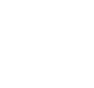

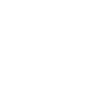

(2)

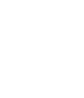

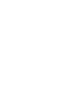

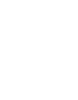

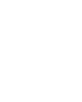

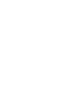
.

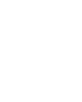
.

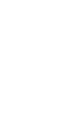

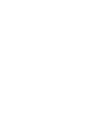

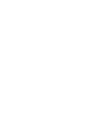

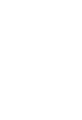

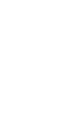

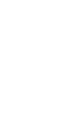

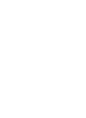
(

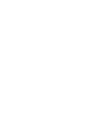

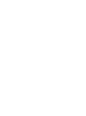

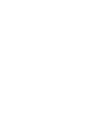

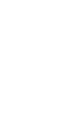

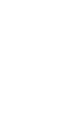

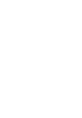

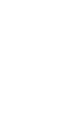

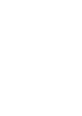


Table 1: $\mathrm{B}, \mathrm{O}$ and $\mathrm{Cl}$ isotopes in OHMIs

\begin{tabular}{|c|c|c|c|c|c|c|}
\hline & ${ }^{7} \mathrm{Cl}$ & $2 \sigma$ & $\delta^{18} \mathbf{O}$ & $2 \sigma$ & $\delta^{11} \mathbf{B}$ & $2 \sigma$ \\
\hline \multicolumn{7}{|c|}{ OHMIs from St. Vincent (Lesser Antilles arc), } \\
\hline svn4b-24 & -0.5 & 0.4 & 4.3 & 0.4 & -7.0 & 2.0 \\
\hline svn4b-36 & -0.4 & 0.3 & 6.0 & 0.2 & 3.9 & 2.2 \\
\hline svn4b-60 & -0.5 & 0.5 & 6.0 & 0.4 & 3.2 & 2.9 \\
\hline svn4b-90a & -0.2 & 0.3 & 5.9 & 0.2 & n.d. & n.d. \\
\hline svn4b-90b & -1.1 & 0.3 & 7.0 & 0.3 & 8.4 & 2.5 \\
\hline svn4b-90v & -0.7 & 0.3 & 6.1 & 0.3 & 6.0 & n.d. \\
\hline $\operatorname{svn} 4 b-164 a$ & 0.2 & 0.2 & 5.1 & 0.2 & 6.4 & 2.0 \\
\hline svn4 & -1.2 & 0.3 & 6.9 & 0.4 & -18.5 & 1.9 \\
\hline svn4b-176a & -0.4 & 0.3 & 4.7 & 0.3 & 7.1 & 2.0 \\
\hline svn4b-181a & 0.6 & 0.3 & 4.4 & 0.3 & 4.5 & 1.9 \\
\hline & -1.7 & 0.2 & 6.9 & 0.4 & 2.0 & 2.2 \\
\hline svn4b-184 & -0.5 & 0.3 & 6.3 & 0.4 & -3.2 & 3.0 \\
\hline svn4b-186 & -0.8 & 0.4 & 6.3 & 0.3 & n.d. & n.d. \\
\hline svn4b-MM1a & -1.3 & 0.3 & 6.3 & 0.1 & 9.1 & 1.6 \\
\hline svn4b-MM2 & -1.1 & 0.4 & 6.2 & 0.4 & 10.8 & 1.6 \\
\hline svn4b-MM3a & -0.1 & 0.3 & 6.1 & 0.7 & 5.9 & 2.0 \\
\hline svn4b-MM7 & -1.9 & 0.5 & 5.3 & 0.2 & 10.3 & 2.4 \\
\hline svn4b-MM15a & -1.2 & 0.3 & 6.1 & 0.4 & 3.7 & 2.4 \\
\hline svn4b-MM22 & -0.8 & 0.3 & 5.4 & 0.3 & 11.7 & 1.9 \\
\hline
\end{tabular}

OHMIs from Aoba (Vanuatu arc)

$\begin{array}{lcccccc}\text { 17-10-b } & -0.4 & 0.2 & \text { n.d. } & \text { n.d. } & 7.9 & 3.2 \\ \text { 17-10-c } & -0.3 & 0.1 & 6.6 & 0.2 & 7.9 & 3.2 \\ \text { 17-16-a } & -1.2 & 0.1 & 6.6 & 0.2 & 4.8 & 3.2 \\ \text { 17-16-b } & -0.7 & 0.2 & 6.0 & 0.2 & 5.8 & 3.2 \\ \text { 3-9 } & -1.4 & 0.7 & 7.0 & 0.2 & \text { n.d. } & \text { n.d. } \\ \text { 3-10 h3-1-a } & -0.9 & 0.2 & 4.4 & 0.2 & 5.6 & 3.2 \\ \text { 3-1-a } & -0.5 & 0.2 & 6.7 & 0.2 & 7.7 & 3.6 \\ \text { 3-1-b } & -0.7 & 0.2 & 6.3 & 0.2 & 8.2 & 3.3 \\ \text { 3-h1-a } & -0.5 & 0.1 & 6.4 & 0.2 & 8.1 & 3.7 \\ \text { 3-4 } & -0.82 & 0.2 & 6.2 & 0.2 & 12.0 & 3.2 \\ \text { 3-5 } & 0.4 & 0.1 & 6.4 & 0.2 & 4.7 & 3.2 \\ \text { 3-6 } & -1.8 & 0.2 & 6.1 & 0.2 & 7.3 & 2.1 \\ \text { 15-1-a } & -0.3 & 0.2 & 6.5 & 0.2 & 5.5 & 3.2 \\ \text { 15-10-a } & -1.2 & 0.3 & 6.1 & 0.2 & 3.4 & 3.2 \\ \text { 15-10-b } & -0.4 & 0.2 & 6.5 & 0.2 & 8.9 & 3.2 \\ \text { OHMIs from Vulcano (Aeolian arc) } & & \\ \text { S1 } & -2.3 & 0.2 & 8.3 & 0.2 & -4.9 & 2.2 \\ \text { S2 } & -2.8 & 0.1 & 8.2 & 0.2 & -5.1 & 1.8 \\ \text { S3 } & -2.5 & 0.1 & 8.0 & 0.2 & -3.1 & 1.8 \\ \text { S7-a } & -2.2 & 0.1 & 8.1 & 0.2 & -9.5 & 1.9 \\ \text { S7-b } & -2.0 & 0.1 & 9.1 & 0.2 & -1.0 & 2.1 \\ \text { S9 } & -2.2 & 0.1 & 8.5 & 0.2 & -3.7 & 1.7\end{array}$


Click here to download Supplementary material for online publication only: SM1.xIsx 
entementar 
Click here to download Supplementary material for online publication only: SM4.xIsx 
